\title{
¿CULMINÓ ZUBIRI EL GIRO PERSONALISTA DE SU FILOSOFÍA PRIMERA? RECONSTRUCCIÓN \\ A DEBATE (A TRAVÉS DE GRACIA, SAN BALDOMERO, COROMINAS Y PINTOR RAMOS)
}

\section{DID ZUBIRI CULMINATE THE TURN TOWARD PERSONALISM OF HIS EARLY PHILOSOPHY? RECONSTRUCTION OF A DEBATE (THROUGH GRACIA, SAN BALDOMERO, COROMINAS AND PINTOR RAMOS)}

\author{
Carlos OrTiz de LANDÁzURI \\ Universidad de Navarra*
}

Resumen: Se reconstruye el debate mantenido entre Gracia, San Baldomero, Corominas y Pintor Ramos acerca del tipo de estrategia moderna, clásica o más bien postmoderna, así como la correspondiente perspectiva ética, metafísica o más bien postmetafísica, desde la que Zubiri (1898-1983) habría elaborado su noción de persona, o más bien personeidad, sin que el cambio terminológico sea en cualquier caso trivial. Este cambio de todos modos habría venido provocado por la pretensión de neutralizar el inevitable carácter paradójico de algunas nociones estrictamente metafísicas de la filosofía primera, como ahora sucede con la noción de substancia, sujeto o persona, que a su vez serán sustituidas por las nociones estrictamente fenomenológicas de substantividad, subjetividad y personeidad, a pesar de dar lugar a nuevos procesos de «reontologización» sin tampoco conseguir resolver todos los problemas que se habían pretendido eliminar. De ahí que Zubiri, tratando de evitarlos, en un momento posterior también llevara a cabo un doble giro retroductivo de tipo ergonómico-sentiente y a la vez intelectual-veritativo, que a su vez mantuvo un cierto paralelismo al doble giro pragmático y a la vez personalista, que también tuvo lugar en numerosas corrientes de la filosofía contemporánea. En este sentido el artículo se interroga no sólo sobre si puede hablarse en Zubiri de un giro personalista de este tipo, con todas las reducciones de tipo fenomenológico que se quieran

* E-mail del autor: cortiz@unav.es 
añadir, sino también si una transformación similar también ocurrió con otras nociones metafísicas que habrían experimentado una reformulación fenomenológica similar, como ahora sucede con los conceptos de verdad, mundo, totalidad con sentido, u horizonte de la comprensión, sin que tampoco en estos casos se trate de un cambio terminológico en sí mismo trivial.

PALABras ClaVe: filosofía primera, fenomenología, metafísica, ontología.

Aвsтract: The debate between Gracia, San Baldomero, Corominas and Pintor Ramos on the type of modern, classical, or rather postmodern strategy, as well as the corresponding ethical, metaphysical, or rather post-metaphysical perspective, based on which Zubiri created his philosophy is reconstructed. In any case, this change would have been provoked by the attempt to neutralise the unavoidably paradoxical character of some strictly phenomenological notions of his early philosophy, making the double pragmatic and personalist twist that operated on the way to base his epistemology clear, although in each case he gave them a very distinct meaning.

KEYwORDs: first philosophy, phenomenology, metaphysics, ontology.

\section{Introducción: ¿¿Fue Zubiri un personalista inclasificable?}

Zubiri (1898-1983) introdujo una transformación fenomenológica de la filosofía primera que a su vez le exigió iniciar una revisión sistemática de la justificación ontológica de los conceptos metafísicos más elementales. A este respecto Zubiri consideró que el significado dado a los conceptos, objetos y representaciones no debería venir determinado preferentemente por las consecuencias que a su vez puedan generar su posterior uso semiótico compartido, al modo como sucedió en el pragmatismo americano de Peirce, James o Dewey ${ }^{1}$. En su lugar más bien Zubiri trató de mostrar cómo la filosofía primera debería introducir un cambio de punto de vista fundamental, a fin de retrotraer el análisis pragmático de las consecuencias a un momento previo capaz de poner de manifiesto la fuerza, energeia o noergía que a su vez permite justificar el tipo de rasgos fenomenológicos que en cada caso se atribuyen a esos mismos objetos, conceptos y representaciones. Al menos esta fue la estrategia seguida por Peirce, Heidegger, Blondel o el

${ }^{1}$ Ortiz de Landázuri, C. «La paradoja de la sustantividad en la filosofía primera de Xavier Zubiri. (Un debate a través de Villanueva, Bañón, Tirado y Rivera)», San Martín, Javier (ed.). Madrid: Las dimensiones de lo humano, UNED, Congreso de la SHAF, 2008, 16-20. 
propio Zubiri para atribuirles determinados rasgos de tipo semiótico, existencial, intencional o simplemente sentiente ${ }^{2}$.

En cualquier caso este último punto de vista noérgico, ergonómico o energético se encuentra muy presente en Zubiri a la hora de definir los conceptos más elementales de la filosofía primera, como ahora sucede con la noción de persona o personeidad, si así se prefiere, o su derivado personalidad. En efecto, esta fue la estrategia seguida por Zubiri para resaltar la peculiar relación autonoérgica, autoergonómica o autoproductiva, que siempre acompaña al proceso de apropiación o reestructuración de aquellos rasgos que uno mismo se asigna. A este respecto Zubiri afirma: «El mismo (hombre) es la persona. Los actos que ejecuta van no solamente calificando al hombre como sujeto que los produce, sino que hay algo más hondo: es que efectivamente esos actos son suyos. (...) Cada uno de esos rasgos va calificando, va configurando de un una manera modal, rasgo a rasgo, la figura de mi propio ser sustantivo. El ser de lo sustantivo es justamente el "yo". No es la persona; es algo distinto: la personalidad que va adquiriendo. Para no confundir los conceptos, me resolví a llamar a la persona, en el sentido que he utilizado esta palabra hasta el momento, personeidad. En cambio personalidad es justamente la figura del ser de lo substantivo que esta persona va cobrando de el inexorable ejercicio de los actos de la vida ${ }^{3}$.

En efecto, sólo en la medida que Zubiri llevó a cabo este primer giro ergonómico-sentiente de tipo retroductivo, también pudo iniciar un subsiguiente análisis de la peculiar génesis noérgica o ergonómica de los restantes rasgos fenomenológicos asignados en cada caso a un concepto, según sean generados de un modo autónomo por uno mismo o por de un modo heterónomo por los demás. Pero de igual forma también consiguió evitar las ulteriores consecuencias tan negativas derivadas del mal uso ontológico, fenomenológico, crítico-transcendental o estrictamente pragmático-transcendental que habitualmente también acabaron haciendo las diversas corrientes del pensamiento contemporáneo de este otro paralelo giro pragmático. En efecto, Zubiri pretendió eludir en todo momento el recurso soterrado que habitualmente las distintas corrientes de pensamiento, especialmente el pragmatismo, seguía haciendo de las nociones de substancia, de sujeto o de persona, en nombre del lenguaje. Es más, con frecuencia se recurría a estos conceptos de la filosofía primera para justificar así los procesos de «re-ontologización» de largo alcance que, finalmente, acabaron siendo muy similares a los

2 Armstrong, De. M. Sketch for a Systematic Metaphysics. Oxford: Oxford University Press, 2010.

3 Zubiri, X. Estructura dinámica de la realidad. Madrid: Alianza, 1989, 224. 
propuestos anteriormente por la metafísica clásica. Sin embargo Zubiri ahora considera que se debería tratar de neutralizar el gran número de paradojas y malentendidos que a su vez generaron estos procesos de «re-ontologización», especialmente cuando este proceso se genera por el mal uso consecuencialista o simplemente pragmatista que, bajo la excusa del lenguaje, en estos casos se solía hacer de las nociones más básicas de la filosofía primera ${ }^{4}$.

Además, en el caso de Zubiri, este nuevo giro ergonómico-sentiente presenta una novedad indiscutible, a saber: obliga a sustituir las nociones ontológicas de substancia, sujeto, hipokeimenon o persona por las correspondientes nociones estrictamente fenomenológicas de sustantividad, subjetividad o personeidad, aunque con una novedad. En efecto, al describir estas nociones ya no se pone el acento en el pretendido carácter «en sí» de este tipo conceptos, objetos o representaciones, sino en su radical bipolaridad respecto de aquel término de referencia esencial frente al que se afirman de un modo fenomenológico a la hora de atribuirse una peculiar noérgia sentiente en sí misma incontestable. Pero igualmente también obliga a introducir un proceso similar a la hora de concebir la noción clásica de ente, ser, bien, o totalidad, para sustituirlas por otras nuevas nociones estrictamente fenomenológicas, como ahora sucederá tanto con la noción de verdad, mundo, totalidad con sentido, horizonte interpretativo o con la propia noción de persona, o personeidad, sin que tampoco en este caso este tipo de cambios terminológicos sea trivial ${ }^{5}$.

\footnotetext{
${ }^{4}$ Schmitz, H. Kurze Einfürung in die Neue Phänomenologie. Freiburg: Alber, 2009.

5 Estas dificultades de tipo terminológico no fueron exclusivas de Zubiri. De hecho Peirce acabaría renunciando al término pragmatismo, inventado por él mismo, y lo sustituyó por el término excesivamente complicado de pragmaticismo, que nunca tuvo excesivo éxito. En efecto, para Peirce el significado de los conceptos, objetos y representaciones debería venir dado por los rasgos semióticos otorgados a cada uno de sus componentes, sin atender exclusivamente al análisis meramente psicológico de las consecuencias que pudiera originar de su uso en común, como propuso William James o más tarde John Dewey. Por su parte, Heidegger, Blondel y el propio Zubiri tampoco coincidieron a la hora de retrotraer el anterior giro pragmático a un nuevo punto de partida fenomenológico de tipo ergonómico, dado que Heidegger consideró que la energeia o actividad atribuida a los objetos debería tener un carácter en sí mismo existencial a fin de poder mostrar la presencia fuera de las causas de cada ente. En cambio Blondel consideró más bien que los rasgos ergonómicos de los objetos y representaciones deberían poder mostrar el carácter intencional de lo finito respecto de una realidad infinita que los abarca completamente; finalmente, en el caso de Zubiri, atribuyó a este tipo de noergia un carácter sentiente en la medida que debía de tener la fuerza suficiente para poner de manifiesto el ámbito intelectual-veritativo al que en cada caso se remite. Sin embargo le otorgó a esta noergia un valor en sí mismo ambivalente, dado que ni exige establecer una diferencia radical última respecto de la realidad total resultante, como afirmó
} 
Además, ahora se hace notar como en el caso de la persona o personeidad se trata de una noción noérgica o ergonómica muy peculiar a la que se asigna una peculiar apertura de tipo fenomenológico respecto del correlato sentiente que en cada caso efectivamente se le asigna. En efecto, en el caso de la persona ya no se genera un encerramiento de los rasgos que se le asignan dentro de un «en sí» inamovible, como en general ocurre de un modo estructural con las demás nociones de la filosofía primera. En su lugar más bien la persona o la personeidad se asigna a sí misma una capacidad bipolar de apropiación y de reestructuración de aquellos rasgos fenomenológicos que configuran a su vez el correspondiente correlato, en virtud precisamente del carácter abierto que se le atribuye. Se le atribuye así a la persona un conjunto de rasgos estructurales bipolares cuya característica fundamental es la capacidad de re-estructuración que tienen. A este respecto afirma Zubiri: “"La apertura modifica el carácter 'en sî́ que tiene la realidad humana. Todas las demás esencias — esencias cerradas las he llamado— lo son, porque son en sí mismas efectivamente de suyo lo que son. Ahora bien, esta apertura no es radical, como si efectivamente las estructuras del en sí fuesen el precipitado existencial de lo que acontece en la vida. No. Ni tampoco es la apertura una especie de apéndice problemático que le acontece al viviente humano: tampoco es esto. Sino que la apertura es una modificación estructural de estructuras que en sí mismas posee el ser humano, la realidad humana" ".

A este respecto la pretensión de este artículo es comparar la reconstrucción de la evolución interna del pensamiento de Xavier Zubiri propuesta por cuatro autores a la hora de elaborar este tipo de conceptos, especialmente el concepto de persona o personeidad, a pesar de recurrir a criterios en gran parte divergentes. En efecto, en unos casos se le asigna a Zubiri un carácter moderno o, por el contrario, clásico, o bien se le atribuye una orientación preferente de tipo ético, metafísico o simplemente postmetafísico. Sin embargo simultáneamente se pretende mostrar como, a pesar de estas discrepancias, es posible reconstruir a lo largo de toda su trayectoria vital un doble giro ergonómico-sentiente e intelectual-veritativo, que a su vez guarda estrechas semejanzas con el doble giro pragmático y a la vez personalista, que también tuvo lugar de un modo retroductivo en numerosas corrientes de la filosofía contemporánea, a pesar de las evidentes diferencias que hubo entre ellas. Pero a pesar de estas discrepancias hay un acuerdo entre todos ellos, a saber: para Zubiri la noción de persona se identifica con la de inteligencia sentiente, en

Heidegger, ni tampoco permite identificar esta realidad total con la esencia infinita divina, como propuso Blondel. Cf. Bastit, M. La Substance. Essai métaphysique. Paris: Parole et Silence, 2012.

${ }_{6}$ Zubiri, X. Estructura dinámica de la realidad. Madrid: Alianza, 1989, 207. 
la medida que logra expresar la capacidad de apropiación y reestructuración de sus respectivos rasgos fenomenológicos, a diferencia de lo que ocurre con el resto de los objetos, conceptos o representaciones ${ }^{7}$.

Evidentemente resulta problemático denominar debate a la reconstrucción de este tipo de procesos, cuando en realidad se trata de encontrar las semejanzas que subsisten tras las indudables discrepancias. Sin embargo se ha mantenido la denominación debate a la reconstrucción comparativa de este tipo de procesos, ya que esta diversidad de propuestas puede llegar a desconcertar inicialmente al posible lector poco habituado a este tipo de planteamientos, haciéndole pensar que hay un ánimo polemista detrás de la atribución de planteamientos tan antitéticos. En efecto, ¿̇es compatible que se diga de un pensamiento que participa de la ruptura moderna respecto de los planteamientos ontológicos o metafísicos, y que simultáneamente se afirme que guarda un fuerte paralelismo con los planteamientos clásicos griegos, como ahora proponen alternativamente Gracia y San Baldomero? ¿Se le puede otorgar a un autor una orientación de tipo preferentemente ontológico o incluso metafísico y simultáneamente resaltar el carácter preferentemente ético o incluso el vacío postmetafísico de sus propuestas, como ahora proponen Corominas y Pintor Ramos? ${ }^{8}$

Evidentemente el pensamiento Zubiri también refleja a lo largo de su evolución numerosas similitudes y discrepancias respecto de numerosos filósofos. Por ejemplo, Gracia resaltará las estrechas semejanzas que Zubiri mantuvo simultáneamente a la vez con los planteamientos fenomenológico-existenciales de Heidegger, con la interpretación raciovitalista de la voluntad de verdad de Ortega y con las propuestas ergonómico-pragmatistas de Blondel. En cambio San Baldomero hará notar más bien las semejanzas con el tipo de cosmovisiones propias de los griegos, en contraposición a las cosmovisiones cristianas. Por su parte Corominas quiere ver en el finitismo intelectual-veritativo de la concepción fenomenológica de persona en Zubiri un eco postmoderno de la persistente actitud ética antitranscendentalista de Levinas, especialmente cuando se posiciona a favor del prójimo, del extraño, del desposeído o de los pobres. Finalmente, Pintor Ramos querrá ver tras los persistentes nudos, paradojas y vacilaciones del pensamiento de Zubiri una actitud postmetafisica reacia a remitirse a un horizonte intelectual-veritativo definitivamente clausurado, al modo como también ocurrió en la fusión de hori-

7 Carroll, J. W.; Markosian, N. An Introduction to Metaphysics, Cambridge: Cambridge University Press, 2010.

${ }^{8}$ Garrett, B. ¿Qué es eso llamado metafisica? Madrid: Alianza, 2010. 
zontes de Gadamer, aunque todo ello se lograra a riesgo de reducir la noción fenomenológica de realidad personal a un mero principio formal vacío de todo contenido esencial propiamente metafísico?.

En cualquier caso la reconstrucción del debate pretende mostrar como la postura de Zubiri nunca se agota en las propuestas de estos diferentes autores a la hora de justificar las nuevas nociones estrictamente fenomenológicas de verdad, mundo, totalidad con sentido, finitismo intelectual-veritativo u horizonte de comprensión. De ahí que el propio Zubiri quedara insatisfecho con sus propuestas, viéndose obligado a ensayar nuevas estrategias a la hora de articular sus anteriores puntos de vista alrededor del proyecto programático de una inteligencia sentiente aún más amplio, siendo sin duda el núcleo central de su legado filosófico. Se trata de mostrar así como Zubiri introdujo un doble giro de carácter preferentemente ergonómico-sentiente e intelectual-veritativo, que pretendió a su vez hacer las veces del paralelo doble giro de tipo pragmático y personalista que se acabó haciendo presente en numerosas corrientes del pensamiento contemporáneo, aunque dándole un carácter fuertemente reproductivo con un objetivo muy preciso: eludir los procesos de creciente «reontologización» que de hecho se acabaron haciendo presentes en aquel anterior doble giro pragmático y personalista, ya tuvieran un carácter crítico-transcendental kantiano o pragmático-transcendental, al modo de Peirce y otros ${ }^{10}$.

Evidentemente estos cuatro autores son testigos de las numerosas fluctuaciones y vacilaciones que experimentó Zubiri a la hora de proponer este doble giro ergonómico-sentiente e intelectual-veritativo, sin que tampoco ninguna de sus respectivas reconstrucciones sea lineal a este respecto. En efecto, en estos casos surge una primera dificultad cuando se advierte la imposibilidad de separar tanto la especificidad de cada giro, como el correspondiente término de comienzo y de llegada o la posible forma de resolverlo. Sin embargo Zubiri no es una excepción a este respecto, sino que algo similar también sucede en la mayoría de los planteamientos pragmatistas y de otras corrientes de pensamiento. En todos estos casos ambos giros se dan entremezclados, de modo que el giro personalista con frecuencia precede y está sobreentendido tras el inicial giro pragmático, y viceversa. Pero de igual modo también el reconocimiento por parte de Zubiri del carácter ergonómico-sentiente de las primeras nociones de la filosofía primera

9 Brandon, R. B. Reason in Philosophy. Animating Ideas, Cambridge: Harvard University Press, 2009.

10 Spaemann, R. Personas. Acerca de la distinción entre «algo» y «alguien». Madrid: Rialp, 2000. 
siempre presupone una soterrada referencia a un peculiar horizonte intelectualveritativo capaz de justificarlas, a pesar de ser este un extremo al que sólo prestó una atención preferente en su última época ${ }^{11}$.

En cualquier caso es indudable la importancia que Zubiri otorgó a la presencia de este doble giro pragmático y personalista en la evolución de las más diversas corrientes del pensamiento contemporáneo. Además, lo consideró como el legado más positivo que a la larga puede ofrecer la filosofía actual, especialmente cuando se toma el esfuerzo suplementario de reorientarlo de una forma compartida aún más satisfactoria, como al menos en su caso pretendió. A este respecto ya en 1959 sus afirmaciones fueron muy rotundas: «El tema de la persona reviste carácter inundatorio en el pensamiento actual. (...) La filosofía, por su lado, sin emplear muchas veces el vocablo, hace de la persona tema de sus reflexiones: cómo el hombre se va haciendo persona a lo largo de su vida. (...) Por donde quiera que se mire, se descubre el tema de la persona como uno de los problemas capitales del pensamiento actual» ${ }^{12}$.

En este contexto es comprensible la postura de numerosos intérpretes que le consideran a Zubiri como un filósofo en permanente proceso de construcción, más volcado hacía lo que todavía quedaba por hacer, que a lo efectivamente realizado. De ahí que el título del artículo se interrogue, ¿Culminó realmente Zubiri el giro personalista? Se pretende así dejar planteada la cuestión acerca de si Zubiri condujo a la filosofía primera a un punto final donde ya la noción persona se pudiera considerar completamente definida; o si más bien su propósito fue formular una persistente llamada a las innumerables posibilidades de desarrollo que puede tener un futuro horizonte intelectual-veritativo donde la persona se pueda definitivamente desarrollar, a pesar de no poder dar nunca por terminado completamente este proceso.

Por lo demás, a lo largo del artículo también se ha mantenido la doble terminología, por un lado, de tipo pragmatista y personalista y, por otra, de tipo ergonómico-sentiente e intelectual-veritativa propia de Zubiri. Se pretende mostrar así un posible paralelismo existente entre la evolución interna del pensamiento de Zubiri y aquel otro tipo de propuestas de tipo fenomenológico, existencial, hermenéutico, teísta, ético o postmetafísico, a pesar de que Zubiri nunca ocultó

${ }^{11}$ Stambovsky, P. Inference and the Metaphysic of Reason. An Onto-Epistemological Critique. Princeton: Marquette University Press, 2009.

12 Zubiri, X. «El hombre, realidad personal», Revista de Occidente, 2. época, 1963, 5-29. 
sus discrepancias con cada una de ellas. En cualquier caso se trata de mostrar el posible influjo que ejercieron en la filosofía de Zubiri la fenomenología de Husserl, el pragmatismo raciovitalista de Ortega, el teísmo-ergonómico de Blondel, el existencialismo agnóstico de Heidegger, los análisis pragmáticos consecuencialistas de Peirce, James o Dewey, o las estrechas similitudes que sus propuestas en ocasiones guardan con Levinas o Gadamer, a pesar de las profundas discrepancias existentes entre todos ellos.

\section{La génesis del primer debate acerca del sentido moderno o clásico de la noción fenomenológica de persona en la filosofía primera de Zubiri}

Zubiri se enfrentó al reto de elaborar una filosofía primera que trató de respetar en todo momento las exigencias tan estrictas que la fenomenología pone a la elaboración de las nociones más básicas del saber, incluida también la noción de persona. A este respecto a Zubiri se le presentó una doble posibilidad de fundamentación de la noción fenomenológica de persona, sin remitirse a los modos clásicos de justificarla mediante la ontología, la metafísica o la filosofía primera, a saber:

a) O bien se inicia un proceso de «desontologización» de la noción de substancia, de sujeto e hipokeimenon, incluida ahora también la noción fenomenológica de persona, para eliminar así todos los residuos metafísicos en sí mismo incognoscibles e inanalizables en el anterior uso ontológico dado a estas nociones, por considerarlos incompatibles con el uso estrictamente fenomenológico de la nueva noción de sustantividad, subjetividad y de personeidad o persona. Sin embargo al hacer esta propuesta tampoco se pudo evitar el recurso a otros presupuestos igualmente extra-fenomenológicos, que a su vez provocaron la aparición de un ulterior proceso de re-ontologización aún más paradójico que el anterior, como sucederá ahora con la noción de substancia y sujeto respecto de la noción de persona. Hasta el punto que Zubiri tuvo que iniciar un posterior giro retroductivo de tipo ergonómico-sentiente, con rasgos muy similares al giro pragmático ocurrido por entonces en diversas corrientes de pensamiento, aunque sin remitirse ya a ningún tipo de presupuesto crítico-transcendental kantiano o pragmático-transcendentales peirceano, como tan habitual suele ser en estos casos. Sólo así Zubiri pudo ejercer un mejor control sobre el posterior uso estrictamente fenomenológico de 
estas nociones elementales de la filosofía primera, como en un artículo anterior ya mostré siguiendo las propuestas de Villanueva ${ }^{13}$ y Bañón ${ }^{14}$.

b) O bien se enmarcan todas estas nociones, incluida la noción fenomenológica de persona, en un horizonte intelectual-veritativo desde el que fuera posible iniciar un proceso de comprensión aún más amplio capaz de abarcar la correspondiente noción de una realidad co-actual total resultante, dando lugar a dos posibilidades: o bien se inicia un segundo giro intelectual-veritativo que permita justificar un posible tránsito fenomenológico sin saltos desde la impresión sentiente de realidad hasta la subsiguiente realidad co-actual total resultante, en la medida que la inteligencia sentiente necesita remitirse a ambos extremos para lograr una efectiva autocomprensión mundanal del ser del hombre entre los demás entes, como en un artículo anterior ya mostré siguiendo a Tirado ${ }^{15}$; o bien se reconoce la necesidad de limitar este horizonte intelectual-veritativo a lo que verdaderamente puede alcanzar una inteligencia sentiente, sin exigirle que salve aquella diferencia radical última que al menos la fenomenología de Heidegger estableció entre el ser y los entes, y que ahora habría que seguir estableciendo entre ambos extremos de aquella misma relación, dando lugar a un sinnúmero de aporías fenomenológicas, como en un artículo anterior mostré siguiendo a Rivera ${ }^{16}$.

Evidentemente la resolución de este doble giro ergonómico-sentiente y a la vez intelectual veritatvivo genera a su vez una circularidad interpretativa. En efecto, dado que ambos giros están mutuamente implicados entre sí, en estos casos la resolución del primer giro conlleva ya una respuesta al segundo, sin que verdaderamente se puedan separar. De todos los cuatro comentaristas de Zubiri ahora analizados, tanto Gracia y San Baldomero, como Corominas y Pintor Ramos, han tratado de analizarlos separadamente. En primer lugar han reconstruido el giro ergonómico-sentiente de tipo retroductivo separadamente, mostrando los presupuestos fenomenológicos desde los que sería posible llevar a cabo un proceso de desontologización como el ahora descrito. Sin embargo, en un momento posterior, también se vieron forzados a reconstruir el segundo giro igualmente retroductivo acerca de la peculiar naturaleza del horizonte intelectual-veritativo

\footnotetext{
13 Villanueva, J. Noología y reología: una relectura de Xavier Zubiri. Pamplona: Eunsa, 1995.

${ }^{14}$ Bañón, J. Metafísica y noología en Zubiri. Salamanca: Universidad Pontificia de Salamanca, 1999.

15 Tirado San Juan, V. M. Intencionalidad, actualidad y esencia: Husserl y Zubiri, Salamanca: Universidad Pontificia de Salamanca, 2002.

${ }^{16}$ Rivera, J. E. Heidegger y Zubiri. Santiago de Chile: Universitaria, Universidad Católica de Chile, 2001.
} 
que fuera capaz de responder a las exigencias tan estrictas ahora impuestas por la fenomenología a las primeras nociones de la filosofía primera, incluida la propia noción de persona. En cualquier caso se trata de un segundo giro interpretativo similar al que en otras corrientes de pensamiento también se establece entre el inicial giro pragmático y el posterior giro personalista, llegando en ambos casos a la conclusión de que difícilmente se pueda dar una respuesta convincente a uno sin abordar su contrario ${ }^{17}$.

En cualquier caso el primer giro ergonómico-sentiente trató de ejercer un mejor control discursivo de las numerosas paradojas y malentendidos generados por el mal uso de algunas nociones más básicas de la filosofía primera, incluida la noción de persona, aunque todo ello exija introducir no sólo un cambio de nombre, sino también una profunda transformación en el modo desontologizador en el modo de concebirlas. Hasta el punto que posteriormente tuvo que iniciar un segundo giro intelectual-veritativo aún más radicalizado que el anterior giro ergonómicosentiente, que le permitió localizar el estricto horizonte fenomenológico desde el que fuera posible la inicial apropiación y posterior reestructuración de este tipo de procesos por parte de la persona, a pesar de tampoco tener garantizada plenamente la correcta resolución del anterior primer giro. En efecto, según estos cuatro autores, esta habría sido la estrategia seguida por Zubiri a la hora de introducir no sólo una nueva noción estrictamente fenomenológica de substancialidad, subjetividad o personeidad, sino también una nueva noción igualmente fenomenológica de verdad, mundo, de totalidad con sentido u horizonte de comprensión, como efectivamente corresponde a una inteligencia verdaderamente sentiente. De todos modos hubo también dos posibles modos preferenciales de abordar este circulo interpretativo que ahora se genera entre ambos giros, a saber ${ }^{18}$ :

a) O bien se atribuye a la persona una capacidad de autorregular la aparición de estas posibles paradojas y malentendidos respecto del uso fenomenológico dado a las primeras nociones de la filosofía primera mediante una estrategia típicamente moderna, al modo como ahora propondrá Diego Gracia. Hasta el punto que ahora se otorgará una prioridad al análisis de los presupuestos ergonómicos-sentientes que a su vez están sobreentendidos tras el recurso en común a una noción estrictamente fenomenológica de verdad, o de la correspondiente voluntad de verdad, por proponerse como una condición de posibilidad y de sentido de la

17 Thomas-Fogiel, I. The Death of Philosophy. Reference and Self-Reference in contemporary Thought, New York: Columbia University Press, 2011.

18 Dancy, J. Introducción a la epistemología contemporánea. Madrid: Tecnos, 2007. 
efectiva constitución de un horizonte intelectual-veritativo verdaderamente fenomenológico, a pesar de no haber abordado explícitamente aquella otra segunda cuestión acerca del principio de apropiación y reestructuración que lleva a cabo todo este proceso ${ }^{19}$.

b) O bien se sigue concibiendo la noción de persona al modo clásico, desde el horizonte interpretativo de una filosofía primera al modo griego, como ahora propondrá San Baldomero. Hasta el punto que ahora se resuelve la posterior aparición de estas posibles paradojas y malentendidos otorgando a las nociones más elementales de la filosofía primera un carácter axiomático o válidos por sí mismo, dando por supuesto que cumplen los requisitos exigidos por el giro ergonómico-sentiente ahora propiciado por la fenomenología ${ }^{20}$.

Se comprueba así como para ambos autores Zubiri reincide en planteamientos similares a los de otras corrientes de pensamiento contemporáneo cuando se trata de abordar el giro pragmático presuponiendo el término final al que se reconduce el giro personalista, antes de haber sometido a ambos a un estricto examen crítico separadamente. Sin embargo la anticipación de una resolución de este tipo es decisiva a la hora de determinar la peculiar naturaleza semiótica, psicológica, intencional, existencial o simplemente ergonómica y sentiente, como al menos sucede en el caso de Zubiri, que se debe atribuir a las correspondientes nociones más elementales de la filosofía primera. En cualquier caso Zubiri presupone ya un concepto de persona o de inteligencia sentiente a la hora de caracterizar fenomenológicamente las nociones más elementales de la filosofía primera, ya se formule desde un planteamiento moderno o clásico ${ }^{21}$. Veámoslo.

\subsection{Gracia, 1986: El giro ergonómico-sentiente zubiriano hacia una estricta noción fenomenológica de persona}

En 1986 Diego Gracia, en Voluntad de verdad. Para leer a Zubiri-VPZ ${ }^{22}$-, ha reconstruido el giro ergonómico-sentiente con el que Zubiri pretendió neutrali-

19 Recanti, F. Perspectival Thought. A Plea for (Moderate) Relativism. Oxford: Oxford University, 2007.

${ }^{20}$ Grimaldi Pizzorno, P. The Ways of Paradox from Lando to Donne. Firenze: Leo S. Olschki, 2007.

${ }^{21}$ Helm, B. W. Love, Friendship and the Self. Intimacy, Identification, and the Social Nature of Persons. Oxford: Oxford University Press, 2010.

${ }^{22}$ Gracia, D. Voluntad de verdad. Para leer a Zubiri. Barcelona: Labor, 1986. 
$z a r$ de un modo responsable las inevitables paradojas y malentendidos generados por el mal uso fenomenológico de algunas nociones básicas de la filosofía primera aristotélica, como ahora sucede con las nociones de substancia, hipokeimenon o sujeto, sin tampoco poderlas sustituir por otras mejores. Sin embargo ahora también se comprueban como Zubiri se encontró con dificultades insuperables, al comprobar como el postulado giro ergonómico-sentiente también podía generar un proceso de «re-ontologización» aún más negativo, similar al que se intentaba evitar, si efectivamente todo quedaba en un simple cambio terminológico de naturaleza trivial. Hasta el punto de tener que atribuir a este posterior giro ergonómico-sentiente un carácter retroductivo típicamente moderno, con la capacidad de fijar las condiciones de validez y de sentido que por su parte deben reunir en general los conceptos, objetos o representaciones para poderlos considerar válidos fenomenológicamente. De este modo la filosofía primera quedó reducida a aquellos conceptos y representaciones a los que se les puede atribuir una fuerza o ergon de carácter sentiente, aunque evidentemente ello exija tener que prescindir de un número de conceptos primeros que no cumplen estas condiciones por ser en sí mismo inobservables, como ahora sigue sucediendo con la substancia, el sujeto o el hipokeimenon aristotélico ${ }^{23}$.

Evidentemente la justificación de este giro ergómico-sentiente tenía un segundo aspecto de más difícil justificación fenomenológica, a saber: la referencia a una realidad co-actual total resultante que de un modo inmediato debería acompañar a la captación de aquella inicial fuerza o ergon de carácter sentiente, sin posibilidad de establecer una fisura o diferencia entre ambas ${ }^{24}$. Sólo así el análisis fenomenológico se podría hacer responsable de la articulación estrictamente ergonómica que ahora se establece entre la inicial impresión sentiente y la realidad coactual resultante, sin necesidad de recurrir a la mediación de ningún tipo de acto mental de tipo intencional, a unas sustantividades actuales de tipo extramental, a la finitud propia de la realidad contingente, o a una naturaleza de tipo existencial, aunque con una dificultad añadida, a saber: Las propuestas de Zubiri tampoco se vieron obligadas a constatar la presencia de una diferencia radical última entre el punto de partida y de llegada de este tipo de procesos, dado que ambos se consideraban igualmente

${ }^{23}$ Braver, L. A Thing of This World. A History of Continental Anti-Realism. Evanston: Northwestern, 2007.

${ }^{24}$ Boulter, S. The Rediscovery of Common Sense Philosophy. Hampshire: Palgrave, 2007. 
accesibles mediante un método estrictamente fenomenológico, a diferencia de lo ocurrido por aquel entonces en Heidegger ${ }^{25}$.

Zubiri siempre defendió la capacidad fenomenológica de justificar este tipo de saltos en virtud del giro ergonómico-sentiente operado en el modo de justificar las nociones más elementales de la filosofía primera, ya que en ese caso no estaríamos en presencia de un salto o una diferencia insalvable, al modo de Heidegger, sino simplemente en presencia de una relación concomitante que se justifica en virtud de la misma fuerza, ergon o noergia sentiente, de naturaleza en sí misma bipolar, referida tanto a los rasgos fenomenológicos del objeto descrito, como aquellos otros rasgos subsidiarios que se ahora se asignan a la realidad coactual total resultante, sin poder otorgar a una más fuerza o relieve que a la otra. Hasta el punto que ahora la correlación entre la inicial impresión sentiente y la realidad coactual total resultante se debería justificar de una forma directa e inmediata, sin poder otorgar mayor fuerza o relieve a una que a otra ${ }^{26}$.

Se genera así una bipolaridad de rasgos fenomenológicos al modo como también suele ser habitual cuando en el giro pragmático se recurre a un conjunto de representaciones o consecuencias a la hora de justificar los rasgos comunes a un conjunto de conceptos o simples objetos. Evidentemente en estos casos siempre se presupone la mediación de un principio constitutivo que se asigna a sí mismo la apropiación y la reestructuración de este tipo de rasgos bipolares, otorgándoles un carácter semiótico, ontológico o más bien ergonómico y sentiente, como ahora sucede con el postulado de una inteligencia sentiente en Zubiri, a pesar de no haberla tematizado todavía de un modo explícito. En cualquier caso para justificar estas conclusiones, según Gracia, Zubiri habría fomentado tres usos sucesivos del método fenomenológico, en razón de las tres épocas en que ahora se divide su trayectoria intelectual ${ }^{27}$, a saber:

a) El inicial periodo fenomenológico entre 1921 y 1928, con su artículo sobre "El pragmatismo» de 1921, con anterioridad a sus oposiciones a la cátedra de Metafísica en 1926. Fue entonces cuando experimentó el tránsito desde las propuestas ergonómico-pragmatistas de Blondel en L'Action hasta este otro modo ergonómico-sentiente a la hora de concebir las nociones más básicas de la filosofía

${ }^{25}$ Haack, S. Evidence and Inquiry. A Pragmatist Reconstruction of Epistemology. Amherst: Prometheus Books, 2009.

26 Strawson, G. Selves. An Essay in Revisionary Metaphysics. Oxford: Oxford University Press, 2009.

27 Hossack, K. The Metaphysics of Knowledge. Oxford: Oxford University, 2007. 
primera. De este modo a partir de entonces concibió las esencias extramentales en razón de la fuerza o ergon que a su vez se les atribuye para otorgarles a una actualidad prioritaria esencial, siempre que incluyan a su vez una referencia a la totalidad actual resultante, sin necesidad de remitirse a la actualidad meramente derivada de los actos mentales intencionales. Además, sólo así se pudo asignar a los correspondientes actos intencionales una radical esencialidad y respectividad fenomenológica en referencia a la correspondiente realidad co-actual total resultante, sin necesidad de remitirse ya en ningún caso ni a una sustancia, ni a un sub-jectum o hipokeimenon racional último aristotélico, cuando ellos mismos se reconocen como fenomenológicamente inobservables ${ }^{28}$.

b) El periodo ontológico de Sobre la esencia - $S E^{29}$ —, que abarca desde 1931 a 1944 y desde 1942 a 1962. Fue entonces cuando habría tratado de ampliar el uso hasta entonces hecho de este nuevo giro ergonómico-sentiente para incluir también la correlación existente entre los actos mentales intencionales, las sustantividades actuales extramentales y la realidad co-actual total a la que ambas se remiten, con tres posibles respuestas, a saber:

1) O bien se justifica la intencionalidad de los conceptos a partir de la peculiar fuerza noérgica o ergonómica generada por una inicial impresión sentiente, que a su vez se concibe como un "hecho" primordial que hace posible esta inicial aproximación a este nuevo tipo de realidad ontológica concreta de cada esencia en particular ${ }^{30}$;

2) O bien se conciben los conceptos como el correlato de una sustantividad actual extramental a la que se asignan un conjunto de rasgos esenciales estrictamente fenomenológicos inherentes a la naturaleza unitaria que se les predica, por considerar que se trata de un nuevo nivel fenomenológico subyacente al anterior $^{31}$;

3) O bien se asignan a esos mismos conceptos una segunda intencionalidad aún más soterrada a la hora de remitirse al horizonte intelectual-veritativo de una

${ }^{28}$ Cf. VPZ, p. 29. Ortiz de Landázuri, C.; «La transformación antropológico-cultural de la noción pragmática de creencia en D’Ors, Ortega, Unamuno y Ganivet», Pérez-Ilzarbe, P. (ed); Pragmatismo hispano, Anuario Filosófico, XL, 2, 2007.

29 Zubiri, X. Sobre la esencia. Madrid: Sociedad de Estudios y Publicaciones, 1962; Alianza, 1985.

${ }^{30}$ Heidegger, M. Posiciones metafisicas fundamentales del pensamiento actual. Ejercicios en el semestre de invierno de 1937-1938. Barcelona: Herder, 2011.

31 Husserl, E. La idea de la fenomenología. Barcelona: Herder, 2012. 
realidad co-actual total. Hasta el punto que ahora este extremo se concibe como un "punto más alto" de intelección al que necesariamente se remite cualquier esencia epistémica en particular, en virtud de la peculiar estructura fenomenológica del comprender ahora asignada a la inteligencia sentiente, y en definitiva a la persona, ya se justifique en virtud de la inicial fuerza noérgica o ergonómica de aquella inicial impresión sentiente, ya se justifique en virtud de la capacidad de apropiación y reestructuración que se asigna a sí misma ${ }^{32}$;

De todos modos Gracia considera que ya entonces aparecieron dificultades insuperables en el proyecto metafísico propuesto en Sobre la esencia. Especialmente cuando se pretendió articular este triple punto de vista epistémico como si fueran efectivamente interdependientes entre sí, cuando en realidad respondían a un mismo proceso ergonómico sentiente bastante similar. En cualquier caso Zubiri en Sobre la esencia mantuvo una estricta separación entre estos tres aspectos: a) por un lado, la peculiar intencionalidad de la mente humana que a su vez revierte sobre la esencia en cada caso considerada; b) por otro, el punto de vista ontológico de la cosa en sí misma considerada de un modo extramental; $\mathrm{y}$, finalmente, $\mathrm{c}$ ) el carácter absoluto asignado a esta realidad co-actual total resultante, que es el punto de vista prioritario que está sobreentendido en todos los demás. Hasta el punto que el proyecto defendido en Sobre la esencia terminó generando un auténtico proceso de «re-ontologización» de estas realidades coactuales totales a las que ahora se remite la filosofía primera. De todos modos Gracia considera que no se puede hacer responsable de este proceso a los residuos metafísicos de las categorías aristotélicas utilizadas de un modo instrumental en estos casos, sino más bien a un intento un tanto desesperado por parte de Zubiri de querer salvaguardar la validez de la metafísica ${ }^{33}$.

Además, para dificultar más los problemas, Zubiri habría superpuesto en Sobre la esencia un segundo giro personalista sobre el anterior giro pragmático. Sólo así pudo hacer depender la efectiva apropiación y reestructuración de los rasgos fenomenológicos, que ahora se atribuyen a una esencia en particular, respecto de la ulterior articulación interna que se introduzca entre aquellos tres puntos de vista previos. Evidentemente este proceso de articulación fenomenológica depende a su vez del recto ejercicio de una voluntad de verdad, según

32 Lévinas, E. Vom Sein zum Seienden; Krewani, A. M.; Krewani, W. N. (Hrsg.). Freiburg: Alber, 2008.

33 Cappelen, H.; Lepore, E. Language Turned on Itself. The Semantics and Pragmatics of Metalinguistic Discourse. Oxford: Oxford University, 2007. 
se decante por una de estas tres posibilidades: a) o se otorga una prioridad a la descripción fenomenológica de las cosas mismas en sí mismas consideradas; b) o se otorga una prioridad al poder reestructurador reflexivo de la intencionalidad de la conciencia frente al mundo; o, finalmente, c) se otorga una prioridad a la reconstrucción del horizonte intelectual-veritativo de una realidad co-actual total resultante, que a su vez estaba sobreentendida desde un principio en aquellos otros dos usos fenomenológicos de los conceptos y representaciones ${ }^{34}$.

De todos modos a lo largo de este segundo periodo Zubiri siguió otorgando una prioridad a la descripción fenomenológica que se alcanza de un modo ergonómico a través de una mera impresión sentiente, concebida a su vez al modo de un hecho primordial, pero sin cuestionar por ello la efectiva prioridad otorgada tradicionalmente a la intencionalidad de los conceptos, como acabará ocurriendo en la fase final de su pensamiento. De ahí que Gracia considere que en este segundo periodo fue como si Zubiri hubiera seguido anclado en un esquema clásico de tipo aristotélico-tomista, $o$ incluso transcendental kantiano, que siguió otorgando una prioridad a la doble intencionalidad directa o refleja de los conceptos sobre la realidad en sí de las esencias o de las primeras impresiones sentientes. En este sentido Gracia reprocha a Sobre la esencia el no haber terminado de apreciar el estricto carácter ergonómico-sentiente al que responden sus propuestas, ya sea respecto de las nociones más elementales de la filosofía primera, o respecto de la propia noción de persona ${ }^{35}$.

c) Finalmente, el período propiamente ergonómico-sentiente de madurez, desde 1962 a 1983, año de publicación de la trilogía Inteligencia sentiente ${ }^{36}$, aunque su gestación habría empezado entre 1942 y 1962, o incluso en el artículo sobre el pragmatismo de 1921, anterior a las oposiciones a cátedra de 1926, como ya antes se ha indicado. Según Gracia, habría sido entonces cuando Zubiri abandonó definitivamente la referencia a un tipo de inteligencia re-ontologizadora, como fue la aristotélico-tomista, o a un tipo subjetividad crítico-transcendental kantiana o pragmático-transcendental peirceana, donde la intencionalidad de los conceptos se justificaba en virtud del indudable alcance metafísico ahora otorgado al posterior uso directo o reflejo de las nociones más

${ }^{34}$ Bater, K. Argument und Argumentation. Logische Grundlagen der Argumentationsanalyse. Göttingen: Vandenhoeck \& Ruprecht, 2007.

35 Millán Puelles, A. La lógica de los conceptos metafísicos. Tomo I: La lógica de los conceptos transcendentales. Tomo II: La articulación de los conceptos extracategoriales. Madrid: Rialp, 2002, 2003.

${ }^{36} \mathrm{Zubiri}, \mathrm{X}$. Inteligencia sentiente. I. Inteligencia y realidad. II. Inteligencia y logos. III. Inteligencia y razón. Madrid: Alianza, 1980-1983. 
elementales de la filosofía primera, cuando su modo de operar debería haber sido totalmente distinto, a saber: iniciar un proceso «desontologizador» capaz de devolver a las nociones más elementales de la filosofía primera su auténticos valor fenomenológico, como ahora también sucederá con la noción de inteligencia sentiente y de persona ${ }^{37}$.

Para Gracia el posible alcance fenomenológico de los conceptos más elementales de la filosofía primera está a su vez regulado por una voluntad de verdad más autocrítica que hace suyas las dos posibilidades antitéticas en donde culmina este proceso: es decir, el reconocimiento de una verdad en virtud de la inicial impresión ergonómica-sentiente que a su vez genera, y los posteriores procesos de apropiación y de reestructuración que la inteligencia sentiente puede introducir tanto respecto del modo de concebir los rasgos fenomenológicos de un objeto, como respecto de la realidad coactual total resultante, incluida la propia realidad personal. En efecto, para Gracia a lo largo de este tercer periodo la voluntad de verdad de Zubiri se afirma, por un lado, como un hecho primordial que deriva directamente de una impresión sentiente. Sin embargo, simultáneamente también se abre al horizonte intelectual-veritativo de una realidad co-actual total resultante, donde a su vez se incluyen la realidad personal que a su vez protagoniza los procesos especulativos de apropiación, reestructuración y reontologización correspondientes. Se trata en cualquier caso de una génesis bipolar de los conceptos más elementales de la filosofía primera que ahora se sigue poniendo en aquella misma impresión sentiente, sin poder ya establecer una disociación absoluta entre ambas dimensiones de este tipo de apertura ${ }^{38}$.

En cualquier caso Gracia reconoce el carácter inevitablemente bipolar que ahora se atribuye a esta estructura previa de la comprensión metafisica estableciendo una estrecha simbiosis fenomenológica entre esta duplicidad de horizontes tan contrapuestos, según se interpreten en clave ergonómica-sentiente o intelectualveritativa, incluyendo ahora de un modo inevitable en este segundo caso una autorreferencia a la realidad personal que a su vez se apropia y reestructura todo este proceso. De este modo ya no sería posible remitirse a una impresión sentiente de realidad sin presuponer la referencia intelectual-veritativa a una previa realidad co-actual total resultante, así como a la correspondiente realidad personal, aunque con una salvedad: a pesar de todas sus afirmaciones en sentido contrario, Zubiri

37 Ales Bello, A. Edmund Husserl: pensare Dio, credere in Dio. Padova: Messaggero, 2005.

38 Goldberg, S. C. (ed.) Internalism and Externalism in Semantics and Epistemology. Oxford: Oxford University, 2007. 
habría asignado este doble horizonte ergonómico-sentiente e intelectual-veritativo a una voluntad de verdad, más autocrítica, sin terminar de advertir que se trata de dos procesos destructivos/reconstructivos totalmente diferentes. De este modo habría justificado un proceso reontologizador. Habría justificado este proceso en sí mismo ambivalente en nombre de una inteligencia sentiente, que a su vez se afirma como una realidad personal capaz de reconocer la fuerza ergonómicasentiente de la correspondiente impresión de realidad. Sin embargo, esta segunda capacidad de apropiarse, reestructurar y reontologizar los rasgos fenomenológicos que ella misma asigna, tanto a las iniciales impresiones de realidad como a la ulterior la realidad coactual total resultante, o incluso a sí misma, sin poder dar nunca por acabado este proceso reontologizador en sí mismo interminable ${ }^{39}$.

Evidentemente esta propuesta se puede volver paradójica si se tiene en cuenta que Zubiri introduce una peculiar correlación diferenciada de niveles fenomenológicos entre el punto de partida y de llegada de este tipo de procesos, sin compartir en ningún caso la diferencia radical última que, según Heidegger, se debería seguir estableciendo de un modo intransitable entre ellos, cuando Zubiri nunca pretendió abordar con tanta radicalidad este tipo de problemas ${ }^{40}$. A este respecto Zubiri habría reconocido, por una parte, la bipolaridad existente entre estos dos posibles enfoques fenomenológicos tan antitéticos, según se remitan a la correspondiente fuerza noérgica sensible, la coactualidad real total resultante y a la respectiva realidad personal, en la medida que este tercer elemento es necesario para poder apropiarse, reestructurar y reontologizar a los otros dos. Por eso también habría reconocido simultáneamente como la captación de un ente, objeto o representación requiere tener en cuenta simultáneamente tanto la fuerza noérgica sensible, la coactualidad real resultante, cómo la realidad personal —es decir, tanto los entes, el ser de los entes, como el Dasein, en terminología heideggeriana-, en la medida que todos ellos se necesitan para cerciorarse del ámbito global donde esa realidad concreta se encuentra inmersa. De todos modos Gracia no terminó de precisar el procedimiento fenomenológico concreto seguido por la voluntad de verdad aún más autocrítica de Zubiri para lograr articular este doble horizonte de la correlación diferenciada de niveles fenomenológicos o de comprensión heideggeriana del ser de los entes, sin por ello generar una absoluta disociación entre ellos. Sólo se nos advierte que para conseguirlo Zubiri se sirvió de una voluntad

39 Husserl, E. Einführung in die Phänomenologie der Erkenntnis. Vorlesung 1909; Schuhmann, E. (Hrsg.); Springer, Dordrecht, 2005.

${ }^{40}$ Gaos, J. Introducción a la fenomenologia', seguida de 'La crítica al psicologismo en Husserl', Madrid: Encuentro, 2007. 
de verdad aún más autocrítica que a su vez tuvo que otorgar un valor veritativo muy diverso a aquellos dos anteriores procedimientos heurísticos en sí mismos antitéticos, sin poder evitar que acabara apareciendo un creciente fisura entre ellos, a pesar de necesitarse mutuamente ${ }^{41}$.

A este respecto Gracia atribuye a Zubiri una creciente disociación entre los dos posibles procedimientos fenomenológicos básicos de acceso a la filosofía primera, a pesar de ser en sí mismos inseparables. Por un lado, la fenomenología objetual de tipo heterónomo mediante la que la ciencia accede de un modo ergonómico-sentiente al hecho incuestionable de la realidad exterior del mundo entorno y de cada uno de los objetos, conceptos y representaciones que a su vez origina, mediante los consiguientes procesos de apropiación, reestructuración y reontologización ya mencionados. Por otro lado la fenomenología fundamental de tipo holista, pero también autorreferencial, mediante el que se accede no sólo al hecho metafísico de la realidad coactual total resultante, sino también al correspondiente hecho protomoral de la correspondiente realidad personal responsable último de estos mismos procesos ahora mencionados. Se trata de dos vías antitéticas, que sin embargo Zubiri habría seguido concibiendo como inseparables ${ }^{42}$.

A este respecto Gracia afirma respecto de Zubiri: «La voluntad de verdad lleva, pues, a la actualización de la realidad y a la realización de mi persona. La realidad se me entrega y yo me entrego a la verdad. Pero esto acontece de maneras distintas, según los modos como la realidad se me hace presente. Para Zubiri son fundamentales dos, el modo "objetual" y el "fundamental”. En la voluntad de verdad real objetual tiene su orto la ciencia, la investigación científica, (...) pero nada más. (...). Es una opción libre de entrega a la realidad por la realidad misma, distinta de otro tipo de entregas no científicas, como de la utilización y aplicación de realidades. A la primera puede denominársela "voluntad de objetualización de la realidad", a la segunda "voluntad de elaboración de la realidad". Son distintas, aunque ciertamente inseparables. No hay elaboración sin objetualización, y viceversa. La voluntad de verdad real recubre a ambas. (...) Pero la realidad no se nos actualiza sólo como "objetual" sino también como "fundamental". En el capítulo dedicado al momento noérgico de la aprensión humana vimos en qué consiste (el hecho ergonómico-sentiente) de la fundamentalidad de la

${ }^{41}$ McGrath, S. J. Heidegger a (Very) Critical Introduction. Eerdmans: Grand Rapid (MI), 2008.

42 Pritchard, D.; Millar, A.; Haddock, A. The Nature and Value of Knowledge. Tree Investigations. Oxford: Oxford University Press, 2010. 
realidad. Ante ella el hombre tiene que optar. Y la opción consiste en entregarse a ella, a la realidad en tanto que fundamento, o en retraerse de ella, convirtiéndola en mero ob-jectum, ob-jeto. Sólo en el primer caso, evidentemente, el hombre habrá optado por (el hecho protomoral) de la "voluntad de fundamentalidad". He aquí lo que buscábamos. (Se trata de) hacer que la fundamentalidad pase a ser la estructura formalmente y expresamente querida de mi propia vida, es hacer que yo viva fundamentalmente» ${ }^{43}$.

Para concluir una reflexión crítica. Diego Gracia describe la filosofía última de Zubiri en el contexto de una modernidad tardía, o incluso de una postmodernidad radicalizada. Concibe su filosofía como una posible síntesis entre la fenomenología de Husserl, la ergonomía-pragmática de Blondel y la voluntad de verdad ortegiana, a pesar de las claras diferencias existentes entre todas estas propuestas. Y a este respecto cabe plantearse. Evidentemente Gracia quiere ver en la voluntad de verdad de Zubiri la irrupción de un nuevo punto de vista ergonómico-sentiente capaz de superar la estrecha simbiosis que el mismo había establecido previamente entre una doble consideración de la esencia, según se la conciba: a) como un hecho primordial sentiente que a su vez se remite a una realidad encerrada en sí misma; b) como un horizonte intelectual-veritativo que a su vez se remite a una realidad co-actual total en sí misma ilimitada, así como de un modo autorreferencial a las capacidades de apropiación, reestructuración y reontologización que ahora se abroga la respectiva realidad personal. De todos modos, al término del proceso, acabaría irrumpiendo finalmente un tercer elemento en discordia, como fue la voluntad de verdad, o hecho protomoral, que permitiría establecer una diferenciación de niveles cada vez más antitética, a la vez que se establece una complementariedad indisociable entre ellos, en la medida que ambos momentos se remiten a una inteligencia sentiente o realidad personal, capaz de articularlos correlativamente ${ }^{44}$.

Y precisamente aquí surge la cuestión crítica: Según Gracia, Zubiri habría recurrido a un tercer elemento en discordia, como es la voluntad de verdad, o hecho protomoral, con la pretensión de articular estos dos posible usos tan antitéticos de la fenomenología, según se oriente hacia la realidad objetual del mundo entorno o al fundamento de una realidad coactual total, incluyendo ahora también la correspondiente realidad personal. Sin embargo Zubiri simultáneamente también atribuye una inseparabilidad en el modo de correlacionase

43 Gracia, D. VVZ, 244; cf. Zubiri, X. El hombre y Dios. Madrid: 1985, 250-1, 255-6.

${ }^{44}$ Hermberg, K. Husserl's Phenomenology. Bristol: Thoemmes, 2005. 
explícitamente, cosa que ahora Gracia no termina de explicar. Y en este sentido cabría plantear: ¿la voluntad de verdad, concebida como un hecho protomoral, es un tercer elemento en discordia que lograr articular estos dos rasgos fenomenológicos antitéticos que definen de un modo autorreferencial a la propia realidad personal, o más bien habría que decir que Zubiri concibe la realidad personal desde un nuevo paradigma relacional cuyo rasgo fenomenológico más característico sería la capacidad de apropiarse y de reestructurar estos distintos niveles fenomenológicos de operar de ella misma, sin necesidad de recurrir a distintos añadidos reontologizadores que ahora se justificarían en nombre de un mero hecho protomoral? Y en ese supuesto, ¿no se hace aún más urgente la necesidad de tematizar la correlación diferenciada de niveles fenomenológicos que, según Zubiri, ahora hay que seguir estableciendo entre el punto de partida y de llegada de este doble tipo de análisis fenomenológicos, en vez de dar lugar a procesos de reontologización y saltos entre niveles fenomenológicos cada vez más ambiciosos que, además, se deberían justificar en nombre de un hecho protomoral? Evidentemente la presencia de estos elementos reontologizadores podría obligar a interpretar las propuestas de Zubiri desde otros planteamientos más clásicos, como otros han hecho ${ }^{45}$. Veámoslo.

\subsection{San Baldomero, 1996: El clasicismo de la subjetividad y de las totalidades de sentido intramundanas zubirianas}

José Manuel San Baldomero en 1996, en La filosofía de Xavier Zubiri versus filosofía griega - $F X Z^{46}$ —, también ha reconstruido la evolución intelectual de Zubiri, mostrando una clara discrepancia respecto de Gracia. En efecto, en su opinión, la filosofía primera de Zubiri habría tratado de neutralizar las inevitables paradojas generadas por el uso estrictamente fenomenológico de algunas de sus nociones básicas de la filosofía primera, como ahora sucede con la noción de un sub-jectum ontológico o hipokeimenon racional y fenomenológicamente inobservable de tipo aristotélico. Además, también habría considerado la consecución de este objetivo introduciendo un giro ergonómico-sentiente en el modo de fundamentar la filosofía primera de Zubiri, Hasta el punto que ya no sería necesario remitirse a las nociones en sí mismas incognoscibles y fenomenológicamente inanalizables de

45 Barrena, S. La razón creativa. Crecimiento y finalidad del ser humano, según C. S. Peirce. Madrid: Rialp, 2007.

46 San Baldomero Ucar, J. M. La filosofía de Xavier Zubiri versus la filosofía griega. Madrid: Fundación Universitaria Española, 1998. 
la ontología aristotélica, sino que más bien bastaría con tener en cuenta la fuerza o noérgia que a su vez acompañan a las primeras impresiones o ergon sentiente generado por los objetos percibidos ${ }^{47}$.

Pero a pesar de este acuerdo básico con las anteriores propuestas de Gracia, sin embargo San Baldomero discrepa en un punto básico. En su opinión, Zubiri siguió respetando dos presupuestos irrenunciables que la filosofía primera clásica compartiría a este respecto con la fenomenología, a saber: 1) el marcado carácter intramundano de este tipo de especulación reflexiva, ya sean de tipo metafísico o fenomenológico; 2) su contraposición al marcado carácter trascendente y sacralizado de la visión teológica cristiana de la subjetividad y de la historia, que de algún modo se habría prolongado de un modo secularizado a lo largo del pensamiento moderno, ya sea kantiano o peirceano. Además, ahora se localizan la presencia de dos rasgos comunes de su fenomenología a lo largo de las tres épocas en que ahora San Baldomero también divide la trayectoria intelectual de Zubiri, a saber ${ }^{48}$ :

a) La radicalización filosófico-fenomenológica inicial, que abarca desde 1931 hasta la publicación de Naturaleza, historia y Dios ${ }^{49}$ en 1945 y Sobre la esencia en 1962. Fue entonces cuando se localizó un nuevo horizonte de filosofía pura, intramundana y libre de dependencias teológicas, común a la fenomenología y a la especulación metafísica griega. En este contexto Zubiri habría concebido la posibilidad de fundamentar una filosofía primera, desde un horizonte de comprensión estrictamente griego más que cristiano, y a partir de tres principios básicos: la noción ergonómico-sentiente de actualidad, el horizonte intelectual-veritativo de mundanidad y la «psyque» o principio anímico vital, sin tampoco remitirse a un hipokeimenon racional último de tipo aristotélico ${ }^{50}$.

b) La profundización metafísica llevada a cabo en la trilogía Inteligencia sentiente (1980-1983). Habría sido entonces cuando concibió tres totalidades de sentido al modo clásico, como ahora sucede con la noción de logos, razón e inteligencia. Además, las habría concebido desde una perspectiva intramundana y libre de dependencias teológicas, con capacidad suficiente para neutralizar por

${ }^{47}$ Simchen, O. Necessary Intentionality. A Study in the Metaphysics of Aboutness. Oxford: Oxford University Press, 2012.

48 Roth, V. M. Das ewige Nun. Ein Paradoxon in der Philosophie des Proklos. Berlin: Duncker und Humblot, 2008.

49 Zubiri, X. Naturaleza, historia y Dios. Madrid: Editora Nacional, 1963.

50 Zubiri, X. Primeros escritos (1921-1926). Madrid: Alianza, 1995. 
sí sola las anteriores paradojas generadas por otros niveles inferiores meramente complementarios ${ }^{51}$.

De todos modos estos procesos, tanto en Grecia como en la actualidad, acabaron dando lugar a ulteriores procesos paradójicos de presunta logificación, de falsa entificación y de abusiva relativización respecto de sus propios presupuestos. Hasta el punto de hacerse necesario remitirse a un nivel de totalidad de sentido superior que a su vez permitiera neutralizar estas posibles paradojas que ahora generan el mal uso estrictamente fenomenológico de los conceptos metafísicos de la filosofía primera. De todos modos, para evitarlos, en ningún caso Zubiri habría recurrido a un horizonte sacralizado de comprensión cristiano, ya sea medieval o moderno, ni tampoco generó un nuevo proceso de fudamentación «ad infinitum», como en ocasiones ocurrió en el modelo griego ${ }^{52}$;

c) Finalmente, en la tercera época, habría llevado a cabo una «refundación» de la metafisica a través de una previa reconstrucción de la pre-estructura metafisica del comprender. Sólo así habría sido posible autorregular de un modo responsable estos anteriores procesos de logificación, de falsa entificación o de relativismo que ella misma puede generar, sin generar tampoco nuevos procesos de re-ontologización aún más negativos. De todos modos ahora esta pre-estructura ya no se puede concebir como un sub-jectum ontológico o hipokeimenon racional aristotélico, que fuera fenomenológicamente inanalizable ${ }^{53}$.

En su lugar se inició más bien un proceso similar al postulado por las categorías hermenéuticas heidegerianas de mundanidad, temporalidad o metafisica, concebidas como totalidades de sentido donde este tipo de principio ergonómico holista se eleva hasta el correspondiente "punto más alto" especulativo, como si se tratara de un rasgo estructural constitutivo de la persona, especialmente cuando se la concibe como «animal de realidades», es decir un principio capaz de articular este tipo de totalidades de sentido a partir de un principio vital común a todas ellas como ahora sucede con la propia «psyque» griega. Hasta el punto que, a partir de este "hecho" primordial de la impresión sentiente de una realidad concreta, le sería posible captar el horizonte transcendental de una realidad co-actual total común a todas ellas, sin «re-ontologizarlas» al modo aristotélico, pero sin

${ }^{51}$ Carlson, J. W. Understanding Our Being. Introduction to Speculative Philosophy in the Perennial Tradition. Washington: CUA - Catholic University of America, 2008.

${ }_{52}$ Moreno, J. I. Para entender mejor el mundo. Curso de introducción a la filosofía realista. Madrid: Rialp, 2007.

53 Millán Puelles, A. Teoría del objeto puro, Madrid: Rialp, 1990. 
tampoco compartir el relativismo historicista y el nihilismo voluntarista defendido por numerosos autores postmodernos. Sólo así sería posible postular una «refundación» de la metafísica a partir de un modelo griego de filosofía primera, al que ahora se considera muy cercano al de la fenomenología, pero que de todos modos se situaría en las antípodas de los procesos de onto-teo-logización cristiana ${ }^{54}$.

Evidentemente San Baldomero sitúa en Aristóteles la génesis de este peculiar modo ergonómico-sentiente de concebir el carácter intramundano de las distintas formas de saber, aunque no lo hiciera con la radicalidad de Zubiri. En efecto, habría sido Aristóteles quien otorgó a la razón un papel decisivo en la apropiación y posterior reestructuración de las distintas formas de saber, Aristóteles habría anticipado así de algún modo las funciones igualmente específicas que en el caso de Zubiri desempeñará la inteligencia sentiente, así como la propia noción de persona, a pesar de reconocer la sistemática ausencia de este concepto en las diversas tendencias de la filosofía griega. En cualquier caso, según San Baldomero, Zubiri habría seguido concibiendo la razón como una posible totalidad dadora de sentido al modo aristotélico; es decir, con una capacidad de apropiarse y reestructurar el carácter ergonómico-sentiente atribuido respectivamente al mundo y a la propia subjetividad o "yo", sin que tampoco en su caso ya se puedan separar ambos extremos de dicha relación ${ }^{55}$.

En este sentido afirma San Baldomero citando a Zubiri: «Lo filosófico de las ciencias filosóficas exige estudiar los distintos modos de la realidad de las cosas. Lo real en cuanto real será el carácter de lo filosófico en cuanto filosófico. Aquí convergen los dos esfuerzos de la búsqueda aristotélica», (pues como afirma Zubiri): «La filosofía propiamente dicha sólo será posible como ciencia, si la realidad de lo real tiene una estructura captable por la razón, si tiene unos principios reales propios (...) de la realidad en cuanto tal. (...) El descubrimiento de la filosofía primera como ciencia de la realidad en cuanto tal sólo fue posible para Aristóteles como término del intento por dar estructura racional al saber filosófico» ${ }^{56}$.

Evidentemente, según Baldomero, Zubiri habría atribuido a Aristóteles una sistemática contraposición y correlación entre las estructuras del mundo y las que la razón se otorga a sí misma. Sólo así Aristóteles habría podido poner de mani-

54 Volpi, F. (ed) Guida a Heidegger. Ermeneutica, fenomenologia, esistenzialismo, ontologia, teologia, estetica, etica, tecnica. Roma: Laterza, 2005.

55 Stalnaker, R. Mere Possibilities. Methaphysical Foundations of Modal Semantics. Princeton: Princeton University Press, 2001.

56 San Baldomero; ibidem, 464-465. cf. Zubiri, X. Naturaleza, Historia y Dios, 106. 
fiesto como a la razón le corresponde desempeñar un papel específico de apropiación, reestructuración y reontologización del mundo que le rodea, haciendo que fuera la subjetividad la que configura las distintas formas de saber, al modo como según Zubiri también sucede con la realidad personal. Sin embargo hay que hacer notar que para Zubiri la noción de persona en cuanto tal tiene su origen en la teología cristiana, sin que aparezca de un modo explícito en Aristóteles, ni tampoco en el resto de las tradiciones de la filosofía griega ${ }^{57}$.

Y a este respecto cabría formular una reflexión crítica respecto de las propuestas de San Baldomero. Evidentemente Zubiri compartió los ideales expresados por el modelo griego de una filosofía primera pura e intramundana. En este contexto Zubiri está más cerca de la concepción griega de la fenomenología que también tuvo Heidegger que de la visión cristiana que defendió Blondel. Sin embargo ahora se pretende justificar este modo griego de justificar la filosofía primera equiparando el papel de la razón al de la persona, cuando este segundo supuesto está totalmente ausente, al menos en Grecia ${ }^{58}$.

Y en este sentido cabría plantear: ¿Se puede atribuir a la filosofía de Zubiri un carácter marcadamente clásico, cuando la noción estrictamente fenomenológica de realidad personal no se puede reconducir a la noción de hipokeimenon, o substancia, aplicada a la subjetividad humana correspondiente, como ocurrió al menos en Aristóteles, ni mucho menos a una psyque o principio vital en sí mismo indiferenciado? ¿Sería suficiente que la filosofía griega hubiera localizado unas determinadas totalidades de sentido estrictamente intramundanas, como ahora sucede con el concepto de mundo o con la propia subjetividad o "yo», cuando anteriormente Gracia había puesto de manifiesto el carácter moderno de la bipolaridad de rasgos estrictamente fenomenológicos que en su caso asigna a la realidad personal? ¿Realmente el modo griego de concebir este último tipo de totalidades de sentido puede salir reforzado cuando previamente habría que establecer entre el punto de partida y de llegada de estos peculiares procesos argumentativos una peculiar correlación diferenciada de niveles fenomenológicos, con sus correspondientes saltos, según Zubiri, hasta el punto de que esta ambiciosa articulación de niveles diferenciados podrían exigir, en nombre de un hecho ergonómico aún más primordial, iniciar unos procesos de reontologi-

57 Rödl, S. Categories of the Temporal. An Inquiry into the Forms of the Finite Intellect. Princeton: Princeton University Press, 2001.

58 Evnine, S. J. Epistemic Dimensions of Personhood. Oxford: Oxford University, 2008. 
zación cada vez más ambiciosos, con las únicas limitaciones que ahora impone la fenomenología?59

En cualquier caso tanto las propuestas de San Baldomero, como las anteriores de Gracia, al igual que habitualmente sucedió en el correspondiente giro pragmático, acabaron ocultando otro debate previo aún más decisivo, que todavía no se ha analizado, a saber: ¿Realmente se pueden reconstruir este peculiar giro ergonómico-sentiente en el modo de concebir la nociones más elementales de la filosofía primera, sin remitirse previamente a una noción de persona o personeidad aún más básica, que debería ser capaz de apropiarse y reestructurar a su vez este peculiar tipo de nociones fenomenológicas elementales? ${ }^{60}$. Veámoslo.

\section{El segundo debate acerca del posible sentido posmoderno del giro personalista zubiriano}

Corominas y Pintor Ramos dieron un vuelco al presente debate cuando siguieron una tercera estrategia típicamente postmoderna, que a su vez trata de situarse por encima de los procedimientos clásicos y modernos, a saber: justificar el horizonte intelectual-veritativo de tipo ético, metafísico o más bien postmetafísico, desde el que ahora se propone el uso compartido de estas nociones estrictamente fenomenológicas de la filosofía primera, a pesar de las evidentes limitaciones que a su vez imponen los correspondientes presupuestos de tipo ergonómico-sentiente. Hasta el punto que en Inteligencia sentiente sólo habrá dos posibilidades de justificar este irrenunciable horizonte intelectual-veritativo: o bien se justifica este horizonte en virtud de una efectiva autorregulación de tipo ético de los respectivos presupuestos de tipo sentiente e intelectual, en la medida que a su vez generan una correlación diferenciada de niveles fenomenológicos que debería estar cada vez más conforme con la capacidad de apropiación, reestructuración y reontologización que ahora la inteligencia sentiente se asigna a si misma, como ahora propondrá Corominas; o bien se reconoce que esta doble correlación diferenciada de niveles de tipo sentiente e intelectual, no sólo deberá estar abierta a ulteriores apropiaciones, reestructuraciones y reontologizaciones de tipo ético por parte de una Inteligencia sentiente, sino que siempre estará abierta a ulteriores procesos «desontologizadores» postmetafísicos aún

59 Dreyfus, H. L. Wrathall, M. A. (eds.); A Companion to Heidegger. Oxford: Blackwell, 2007.

${ }^{60}$ Cf. SE, p. 9 y 33. Schmitz, K. L.; O'Herron, P. (eds.); The Texture of Being. Essays in First Philosophy. Washington: CUA-Catholic University of America, 2007. 
más radicalizados respecto de la propia noción de persona, a pesar de que el propio Zubiri tampoco habría prestado excesivo interés a esta misma posibilidad, como ahora propondrá Pintor Ramos ${ }^{61}$.

En cualquier caso Corominas y Pintor Ramos pretendieron justificar el valor de la filosofía primera en virtud del peculiar horizonte intelectual-veritativo de comprensión compartida que de un modo moral y metafísico o más bien postmetafísico, a su vez genera la inteligencia sentiente. Hasta el punto que según estos dos autores ya no sólo caben los planteamientos modernos o clásicos acerca de este saber, sino que a su vez se les podría otorgar indistintamente una orientación de tipo ético, metafísico o más bien postmetafísico cada vez más diversificado y abierto. Hasta el punto que ambos autores también reconocieron los posibles malentendidos éticos y metafísicos, o más bien postmetafísicos, de los que puede ser objeto un uso incorrecto del anterior doble giro ergonómico-sentiente e intelectual-veritativo llevado a cabo por Zubiri, salvo que se adopte uno de estos dos puntos de vista ${ }^{62}$ :

a) o bien se toma la noción de persona como un hecho protomoral en virtud del cual la inteligencia sentiente es capaz de justificar el punto de partida de filosofía primera. En efecto, en este caso la filosofía primera ya no sólo se justifica en virtud del hecho primordial de aquel tipo de imprensión sentiente que a su vez remite a una realidad concreta, sino que además se constata un segundo hecho protomoral mediante el que la persona se atribuye a si misma un capacidad de apropiación, reestructuración y reontologización de sus propios rasgos fenomenológicos, sin quedarse en un mera captación de aspectos meramente superficiales o utilitarios. Hasta el punto que ahora la noción de persona también seguirá haciendo referencia a un horizonte intelectual-veritativo mucho más amplio, de modo que ya no sólo debe incluir una referencia a la dimensión ergonómico-sentiente de las nociones más básicas de la filosofía primera, sino también a aquellas otras dimensiones más altas y decisivas cuya regulación pertenecen exclusivamente a la propia persona. Al menos así sucederá con las relaciones de religación o de simple obligación que se establece entre estos dos niveles anteriores de compresión recíproca, como son el ergonómico-sentiente y el intelectual-veritativo respectiva-

${ }^{61}$ Nicolás, J. A.; Frápoli, M. J. (ed.) Teorías contemporáneas de la verdad. Madrid: Alianza, 2012.

${ }^{62}$ Sokolowski, R. Phenomenology of the Human Person. Cambridge: Cambridge University, 2008 . 
mente, cuya fijación dependerá ya exclusivamente de los niveles de autonomía fenomenológica que la persona se asigna a sí misma ${ }^{63}$;

b) o bien se toma la noción de persona como el punto arquimédico metafísico o más bien postmetafísico, que hace posible la resolución de la multitud de nudos gordianos o simples paradojas que ahora rodean a la formulación de las nociones más elementales de la filosofía primera, en la medida que ella misma se apropia una capacidad de reestructurar la posible resolución positiva dada a estos mismos nudos o paradojas, como ahora va a afirmar Pintor Ramos. En efecto, ahora se considera que este tipo de nudos y paradojas fueron producidos en todo caso por los procesos «re-ontologizadores» respecto del mal uso dado por las motivaciones más diversas a las anteriores nociones más elementales de la filosofía primera. Sin embargo Pintor Ramos opina que el mismo principio que originó el problema, debería también ser el más apropiado para resolverlo, en la medida que la persona también dispone de las más diversificadas estrategias de apropiación, reestructuración y reontologización capaces de contrarrestarlos. De todos modos ahora se piensa que Zubiri sólo se habría hecho cargo del problema en las fases más tardías de su filosofía, dando una prioridad al problema de la realidad, sin acabar de apreciar el papel crucial que sin duda le corresponde a la noción de persona en este proceso ${ }^{64}$. Veámoslo.

\subsection{Corominas, 2000: El horizonte ético posmoderno de la noción fenomenológica de persona en la filosofía primera de Zubiri}

Jordi Corominas en 2000 ha defendido en Ética primera. Aportación de X. Zubiri al debate ético contemporáneo -EPZ ${ }^{65}$ - la necesidad de justificar la filosofía primera en virtud de la orientación de tipo ético que siempre se puede otorgar al peculiar horizonte intelectual-veritativo en el que se encuadra la filosofía primera. En efecto, si el objetivo principal de la filosofía primera para Zubiri es tratar de llevar a cabo una efectiva neutralización de las inevitables paradojas generadas a su vez por los procesos de «re-ontologización» generados por el pensamiento moderno o clásico. Hasta el punto de que si se comprueba la presencia

${ }^{63}$ Ehring, D. Tropes. Properties, Objects, and Mental Causation. Oxford: Oxford University Press, 2011.

${ }^{64}$ Wernecke, J.; Handeln und Bedeutung. L. Wittgenstein, Ch. S. Peirce und M. Heidegger zu einer Propädeutik einer hermeneutischen Pragmatik. Berlin: Duncker und Humblot, 2007.

${ }^{65}$ Corominas, J. Ética primera. Aportación de X. Zubiri al debate ético contemporáneo. Bilbao: Desclée de Brouwer, 2000. 
abusiva de la filosofía primera por parte de su anterior giro ergonómico-sentiente, entonces se hace necesario legitimar este tipo de procesos al menos en virtud de razones de tipo ético. En este sentido una posible autorregulación responsable del subsiguiente proceso de re-ontologización abusiva hacia el que se podría orientar este mismo horizonte intelectual-veritativo de la filosofía primera debería dar un paso previo irrenunciable, a saber: reconocer la presencia latente de una pre-estructura metafísica del comprender desde la que se hace posible reconocer el horizonte heuristico-moral e intelectual-veritativo hacia el que ahora se orienta todo este tipo de procesos, sin necesidad de remitirse de un modo extrafenomenológico a un hipokeimenon racional último de tipo aristotélico, o a unos presupuestos critico-transcendentales, de tipo kantiano o a unos presupuestos pragmático-transcendentales, al modo de Peirce ${ }^{66}$.

En efecto, según Corominas, Zubiri ya desde los inicios de su trayectoria intelectual habría sustituido el recurso a unos procedimientos consecuencialista de tipo pragmático, por otros procedimientos ergonómicos de tipo vitalista, o simplemente sentientes, mediante los que confió resolver las numerosas paradojas y malentendidos que a su vez podría generar el recurso abusivo a determinados procedimientos de tipo ontológico, fenomenológico, semiótico o de tipo especulativo-racional, ya se fundamentaran en Husserl, Kant, Peirce o Aristóteles. Sin embargo Corominas considera que esta no fue la última palabra de Zubiri a este respecto, sino que posteriormente la completó con lo que ahora se denomina el mejor Zubiri de la trilogía Inteligencia sentiente, cuando prolongó sus anteriores propuestas hacia el futuro, imprimiéndoles una clara orientación ética que en su caso sobreviene respecto de aquella otra dimensión meramente ergonómica o sentiente ${ }^{67}$.

En efecto, habría sido en esta última época cuando Ignacio Ellacuría ejerció un persistente influjo sobre Zubiri, con anterioridad incluso a la publicación de Sobre la esencia (1962), una obra decisiva, a pesar de haber sido muy mal recibida y peor interpretada. Sin embargo Zubiri nunca se arrepintió de haberla escrito, ni la consideró un fracaso. Más bien siempre la vio como el punto de partida de un giro intelectual-veritativo o personalista donde prevaleció la necesidad de justificar un uso de la noción de esencia entre las varias posibles, sin poder dejar de lado en este caso las razones de tipo moral. Desde entonces Zubiri habría otorgado

${ }^{66}$ Migliori, M. Plato' Sophist. Value and Limitation of Ontology. Five Lessons Followed by a Discussion, Academia, Sankt Augustin, 2007.

${ }^{67}$ Dougherty, T. (ed.) Evidentialism and Its Discontents. Oxford: Oxford University Press, 2011. 
un especial al protagonismo en la elaboración de su proyecto metafísico a la referencia a un horizonte intelectual-veritativo, con orientación de tipo heuristicomoral. Es decir, un proyecto claramente a favor de una decisiva potenciación de la doble vertiente metafísica y moral, intelectual y sensible que ahora presenta el proyecto de una inteligencia sentiente. Al menos este fue el objetivo principal de la reconstrucción que Corominas y Vicens hicieron de su trayectoria intelectual en 2006, cuando publicaron: Xavier Zubiri. La soledad sonora ${ }^{68}$.

Según Corominas y Vicens, la referencia a este nuevo horizonte de carácter heurístico-moral habría que situarla preferentemente en el punto de partida de la trilogía Inteligencia sentiente. En efecto, fue entonces cuando trató de hacer compatible el «hecho» primordial o arquimédico de una impresión sentiente con su posterior referencia al horizonte transcendental de una realidad co-actual total cada vez más ilimitada. Sin embargo ya entonces el propio método fenomenológico acabaría introduciendo una progresiva limitación a la hora de justificar estas peculiares totalidades de sentido efectivamente sentientes, como ahora sucede con la noción de mundo, subjetividad y otras similares. En efecto, fue entonces cuando Zubiri constató la presencia entre el punto de partida y de llegada de este tipo de procesos de una correlación diferenciada de niveles fenomenológicos, al igual que Heidegger también localizó una diferencia radical última entre ellos. Sin embargo, en Zubiri ya no fue posible iniciar un proceso de «re-ontologización» que pudiera legitimar estos sucesivos saltos de niveles fenomenológicos desde un punto de vista metafísico. De igual modo que en Heidegger tampoco se pudo justificar un posible tránsito hasta el ser a partir de los entes ${ }^{69}$.

En efecto, según Corominas, habría sido en el último tercer y último periodo de la trayectoria intelectual cuando Zubiri habría hecho responsable de los abusivos procesos de «reontologización» a ocultas motivaciones éticas, sin poderlos justificar en virtud de razones estrictamente fenomenológicas. Hasta el punto que ahora se produce un proceso de des-ontologización similar de algún modo al propuesto por Levinas, cuando en virtud de razones éticas se exige relativizar los anteriores análisis fenomenológicos de tipo ontológico, vitalista, antropológico de sus dos épocas anteriores. A su modo de ver este es el único modo como se puede anteponer un nuevo punto de vista ético más radical, que a su vez estaba sobreentendido en sus anteriores puntos de vista, a saber: la necesidad de hacer

${ }^{68}$ Corominas, J.; Vicens, J. A. Xavier Zubiri. La soledad sonora. Madrid: Taurus, 2006.

${ }^{69}$ Honneth, A.; Rössler, B. (Hg.) Von Person zu Person. Zur Moralität persönlicher Beziehungen. Frankfurt: Suhrkamp, 2008. 
referencia a un nuevo horizonte heurístico-moral generado a su vez por la alteridad que supone la presencia del otro; es decir, la necesidad de mantener una referencia al diferente, al prójimo, al extranjero o, en definitiva, al pobre ${ }^{70}$.

De este modo Zubiri habría concebido la filosofía primera en este tercer período como una ética primera, que exige anteponer al punto de vista fenomenológico este otro estrictamente moral o ético. Hasta el punto que ahora la filosofía se remite a un horizonte ético de comprensión que se afirma como un simple hecho protomoral o trasmoral; es decir, como un punto de partida irrefutable que a su vez permite regular las posteriores relaciones de religación y de obligación, de alteridad institucional y de simple justicia, que son inherentes a los futuros procesos de globalización multicultural y a las correspondientes totalidades de sentido a ellas asociadas. En este contexto se considera absolutamente prioritario el necesario compromiso u opción preferencial a favor de los pobres, a pesar de que sus concreciones siempre seguirán adoleciendo de un carácter estructural, fáctico y transmoral, ya se formulen de forma anónima o compartida ${ }^{71}$.

Por eso afirma Corominas: «el hecho moral (...) nos exige que, antes de las intenciones, consideremos su carácter fáctico. (...) La moral (...) se suele separar de lo fáctico cuando de hecho la norma, la ley moral, los deberes, los tabúes y los valores están siempre encarnados en la actuación, están siempre esculpiéndola. (...) Finalmente el hecho transmoral (...) nos lleva a crear nuevas actuaciones (...) de modo que siempre estamos recodificando nuestra conducta y sometiéndola a nuevos regímenes morales» ${ }^{72}$.

Evidentemente esta justificación de la filosofía primera a partir del hecho moral genera circulos viciosos y paradojas interminables, salvo que se fundamente este mismo punto de partida a partir de una noción adecuada de persona, que logre neutralizar y desactivas estos procesos desde dentro de sí mismos. Por eso Corominas también había afirmado anteriormente: «¿No estaríamos ante un círculo vicioso? ¿Cómo puede un punto de partida fáctico y moral fundamentarse por sí mismo? A este respecto hemos definido moral como apropiación de

70 Nida-Rümelin, J.Verantwortung, Stuttgart: Reclam, 2011.

71 Taylor, J. S. (ed.) Personal Autonomy. New Essays on Personal Autonomy and Its Role in Comtemporary Moral Philosophy. Cambridge: Cambridge University, 2005.

72 Cf. EPZ, pp. 343-345. Lowe, E. J.; Personal Agency. The Metaphysics of Mind and Action. Oxford: Oxford University, 2008. 
posibilidades. Toda actuación humana es moral, en la medida que implica una apropiación de posibilidades que no es unívoca y que no está prefijada, como en el animal, por un sistema estimúlico. (...) Zubiri nos dirá que es un momento trasmoral de toda moral, pero que incluye una moral concreta. A este momento transmoral que exige una moral concreta es a lo que llamamos, con Diego Gracia, hecho protomorali ${ }^{73}$.

Y es precisamente aquí donde surgen algunas cuestiones, que Corominas deja sin explicar: dado que ahora se concibe la propia actividad ética como un hecho protomoral autorregulado por la persona, ¿no habría que concluir que ahora que el interés de Corominas se fija preferentemente en los rasgos fenomenológicos de la personalidad o carácter, que precisamente se fraguan mediante el seguimiento de una norma moral concreta, sin tampoco profundizar en el constitutivo fenomenológico esencial de la persona, volviendo de algún modo a las propuestas de Gracia? Por otro lado, dado que Zubiri tampoco compartió el establecimiento de una diferencia radical última intransitable entre el ser y los entes, al modo de Heidegger, ¿no se debería haber concluido que la opción preferencial a favor de los pobres pone de manifiesto el papel decisivo de la persona en la regulación o más bien autorregulación ética de la correlación diferenciada existente entre los diversos niveles fenomenológicos, sin poderla considerar un simple espectador imparcial de todo este proceso? ${ }^{74}$

Finalmente, dado que Zubiri admitió dos formas posibles de lograr una posible correlación diferenciada entre los diversos niveles fenomenológicos existentes, como fueron especialmente las relaciones de religación y de obligación recíproca que a su vez cada realidad singular establece con la totalidad de sentido correspondiente, ¿no se debería haber justificado los presupuestos metafísicos, o en su caso postmetafísicos, que a su vez las hacen posibles? En cualquier caso Corominas no analizó los peculiares presupuestos metafísicos, o en su caso postmetafísicos, desde los que Zubiri habría otorgado una prioridad absoluta a la dimensión heurístico-moral de la fenomenología respecto de otros posibles puntos de vista. Sin embargo otros lo han hecho ${ }^{75}$. Veámoslo.

73 Corominas, J. EP., 319-321; Zubiri, X.; PTHC, 72.

74 Schmidinger, H.; Sedmak, C. (Hrsg.); Der Mensch - eine Kreatives Wesen? Kunst, Technik, Innovation. Darmstadt: Wissenschaftliche Buchgeselschaft, 2008.

75 Kitcher, Ph. The Ethical Proyect, Harvard Universityy Press, Cambtridge (MA), 2011. 


\subsection{Pintor Ramos, 2006: El vaciamiento posmetafísico de la noción fenomenológica de persona relacional en la filosofía primera de Zubiri}

Pintor Ramos en 2006, en Nudos en la filosofía de Zubiri -NFZ ${ }^{76}$ — ha analizado la irrupción del problema postmetafísico de la persona a la hora de neutralizar las inevitables paradojas y malentendidos originados por este tipo de procesos, a pesar de que Zubiri tampoco se lo habría propuesto. En efecto, ahora se comparte el doble giro ergonómico-sentiente e intelectual-veritativo que Zubiri introdujo a la hora de justificar un uso aún más estricto de la noción fenomenológica de persona, a pesar del subsistir el peligro de generar a su vez distintos procesos de re-ontologización aún mas abusiva de los que anteriormente ya había generado a este respecto la filosofía moderna o clásica ${ }^{77}$. De ahí que ahora se considere que cualquier proyecto de «refundación» de la filosofía primera debe comenzar con una denuncia de los posibles abusos que en este mismo proceso se puedan volver a generar, dada la imposibilidad de evitarlos totalmente. De este modo Pintor Ramos sitúa la filosofía primera de Zubiri más allá del marcado carácter heurístico-moral que le había asignado Corominas, para marcarle un claro cometido postmetafísico. En efecto, el cometido principal ahora de la filosofía primera es tratar de eludir los errores generados por la re-ontologización de las diversas formas de saber, en la medida que el rasgo fenomenológico principal atribuido a la persona sería tomarla como la responsable principal tanto de este tipo de denuncias como de su posible resolución. Además, ahora se retrotrae este tipo de consideraciones a los inicios de su trayectoria intelectual, a su artículo de 1921 sobre el "pragmatismo», con anterioridad a las oposiciones a cátedra de $1926^{78}$.

En efecto, habría sido en dicha lección cuando se distanció definitivamente de los análisis semióticos de tipo consecuencialista de Peirce, James y Dewey principalmente, por considerar que hacían responsable del problema al lenguaje, en vez de atribuírselo a su agente principal, la persona. Hasta el punto que consideró una terea inaplazable la elaboración de una flosofía primera, concebida al modo de una metafísica, o más bien de una posmetafísica, donde se justificara el papel primordial desempeńado por la persona en este tipo de procesos. En

76 Pintor-Ramos, Antonio; Nudos en la filosofía de Zubiri. Salamanca: Universidad Pontificia de Salamanca, 2006.

77 Pattison, G. God and Being. An Inquiry. Oxford: Oxford University Press, 2011.

78 San Martín, J., Domingo Moratalla, T. (eds.) Las dimensiones de lo humano, Ortega, Zubiri, Marías y Lain Entralgo. Madrid: Biblioteca Nueva, Fundación Ortega y Gasset, 2010. 
cualquier caso el propósito fundamental de la filosofía primera no se reduce a la simple resolución pragmática de nudos paradójicos o gordianos, como sucede en otras numerosas corrientes de pensamiento contemporáneo ${ }^{79}$.

Por el contrario, según Zubiri, su cometido principal debe ser tratar de evitar la futura aparición de nuevos nudos paradójicos o gordianos todavía más intrincados, que podrían venir provocados por los procesos de «re-ontologización» ya sea de la realidad mundanal, como de la propia noción de subjetividad o persona. De ahí que Zubiri se viera obligado a postular una radical inversión en el modo de concebir el horizonte intelectual-veritativo del comprender fenomenológico. En efecto, dado que ahora tampoco se puede evitar ya la aparición de un proceso al infinito de aparición de sucesivos nudos de carácter cada vez más aporético, tampoco se puede garantizar la futura consecución de una definitiva filosofía primera, ya sea al modo moderno o al clásico. De ahí que ahora se sugiera que Zubiri más bien volvió a postular una sucesiva fusión de horizontes nunca totalmente conmensurables entre sí, al modo como también sucede en la filosofía de Gadamer ${ }^{80}$.

Evidentemente Zubiri también reconoce la necesidad de remitirse a un peculiar horizonte intelectual-veritativo de tipo metafisico, o más bien postmetafísico que, como ahora también sucede con la inteligencia sentiente, tiene un rasgo fundamental: la capacidad de apropiarse, reestructurar y reontologizar todo este proceso, teniendo que asumir la persona la responsabilidad específica que a este respecto le corresponde. Es decir, siendo capaz de reconocer la radical inversión que la propia persona genera, en primer lugar, mediante el recurso fenomenológico a los anteriores presupuestos ergonómicos-sentientes e intelectual-veritativos; y en segundo lugar, generando una inversión aún mayor al hacer suya la capacidad de apropiarse, reestructurar y reontologizar la interacción recíproca que ahora se establece entre el punto de partida y de llegada de este tipo de procesos, sin por ello dejar de separarlos como dos momentos antitéticos ${ }^{81}$. A este respecto Zubiri separa dos momentos:

a) por un lado, la fuerza ergonómica o noérgica que está generada por una simple impresión sentiente de una realidad concreta, pero que siempre debe estar abierta a su posible reinterpretación en un sentido contrario o diferente al inicial-

79 Gertler, B.; Self-Knowledge. London: Routledge, 2011.

${ }^{80}$ Loux, M. J.; Metaphysics. A Contemporary Introduction. Abingdon: Routledge, 2006.

${ }^{81}$ Preyer, G.; Peter, G.; Context-Sensivity and Semantric Minimalism. New Essays on Semantics and Pragmatics. Oxford: Oxford University, 2007. 
mente propuesto en la medida que se puede acabar englobando en una totalidad de sentido totalmente diferente a la inicial ${ }^{82}$; y por otro lado:

b) el horizonte fenomenológico de una realidad co-actual total resultante, que siempre estará limitado por la referencia mundanal a la peculiar noérgia sentiente que a su vez lo ha originado, pero que simultáneamente también permite fomentar una apertura ilimitada a un horizonte de comprensión aún más alto, sin poder asegurar en ningún momento haber alcanzado la meta máxima a la que se aspira. Hasta el punto de concebir al primero como un simple "hecho" primordial fenomenológico en sí mismo ambivalente y al segundo como un "punto aún más alto» de interminable prosecución fenomenológica, pudiendo siempre originar la aparición de nuevos nudos gordianos y paradojas aún más aporéticas, sin poder neutralizarlos ni tampoco eludirlos ${ }^{83}$.

A este respecto Pintor-Ramos sitúa a Zubiri dentro de una forma de pensamiento postmetafísico aún más radicalizado, aunque con una particularidad: en su caso la aparición de este tipo de nudos gordianos o situaciones paradójicas deja de ser un defecto y se convierte en una virtud, tomándolas incluso como el punto de partida y de llegada de su metafísica, o más bien de una posmetafísica más estrictamente fenomenológica. De este modo los nudos paradójicos de Zubiri acaban guardando una cierta semejanza con el círculo hermenéutico que Gadamer estableció como consecuencia de la correspondiente fusión de horizontes. Con el añadido de que también ahora deja de establecerse una inconmensurabilidad recíproca en sí misma viciosa entre dichos nudos gordianos, para transformarse en una correlación diferenciada de niveles fenomenológicos en sí misma virtuosa. Hasta el punto que la aparición de este tipo de nudos paradójicos exige iniciar una relativización sistemática de ambos extremos de este tipo de correlaciones diferenciadas, sin por ello fomentar un escepticismo paralizante en sí mismo vicioso. En su lugar más bien siempre es posible postular una nueva reformulación aún más virtuosa en el modo de conceptualizar estas nociones más comunes de la filosofía primera, sin que se pueda poner un término final a este proceso de reestructuraciones en sí mismo interminable. Desde esta perspectiva ahora se separaran cuatro épocas de tipo revisionista, criticista, sapiencial y de consolidación final en la progresiva evolución del pensamiento de Zubiri ${ }^{84}$ :

82 Sousa, R. de; Emotional Truth. Oxford: Oxford University Press, 2011.

${ }^{83}$ Husserl, E.; Meditaciones cartesianas. Presas, M. A. (ed). Madrid: Tecnos, 2006.

${ }^{84}$ Inwagen, P. van; Zimmerman, D. W.; Metaphysics. The Big Question. Cambridge: Blackwell, 2008. 
1) La etapa revisionista desde la fenomenológica-positivista de 1918 hasta su regreso de Alemania en 1931. Fue entonces cuando hizo numerosas propuestas claramente revisionistas respecto del pragmatismo vulgar de numerosas corrientes de pensamiento continental, donde se propugnaba una interpretación de tipo consecuencialista respecto del uso semiótico que en cada caso se hacía de los objetos, conceptos y representaciones mediante la aplicación de una máxima pragmática ${ }^{85}$

2) La etapa criticista cuando sustituyó el recurso a una verdad adecuación u ontológica por el análisis de aquellos presupuestos de tipo ergonómico-sentiente, que a su vez hacen posible el uso compartido de estas nociones más básicas de la filosofía primera. De todos modos durante este período siguió manteniendo otros posibles usos lógicos y ontológicos de estas mismas nociones, como si no hubiera acabado de advertir la radicalidad de sus propias propuestas y la incompatibilidad con los planteamientos clásicos, al menos si se sigue un planteamiento estrictamente fenomenológico ${ }^{86}$;

3) La etapa central de tipo sapiencial, a partir de 1945, que culminaría con la publicación de Sobre la esencia en 1962, la obra más original y más malinterpretada de todas, donde Zubiri acabaría adoptando una actitud rigurosamente metafísica o más bien postmetafísica. Según Pintor Ramos, Zubiri habría utilizado entonces una terminología fenomenológica particularmente exigente que en nada contribuyó a su adecuada interpretación. Además, no se conformó con una fundamentación meramente ontológica, pragmático-vulgar o simplemente ética, de estas nociones más básicas de la filosofía primera. En su lugar más bien se considera que cada noción hace una referencia bipolar a dos extremos antitéticos, a saber: por un lado, el punto de partida estrictamente ergonómicosentiente, como son las iniciales impresiones inmediatas, en contraste con lo que ocurría en la ontología clásica; y por otro, la referencia fenomenológica a un horizonte intelectual-veritativo en la medida que se afirma como una dimensión indisociable de la anterior ${ }^{87}$.

85 Schultenover, D. G. (ed.); The Reception of Pragmatism and the Rise of Roman Catholic Modernism, 1890-1914. Washington: Catholic University of America Press, 2009.

${ }^{86}$ Merriks, T.; Truth and Ontology. Oxford: Clarendon, Oxford University, 2007.

87 Springge, T. L. S. The Importance of Subjectivity. Selected Essays in Metaphysics and Ethics, McHenry, L. (ed.); Oxford University Press, Oxford, 2011. 
De todos modos en Sobre la esencia pretendió seguir justificando la complementariedad entre las propuestas fenomenológicas y las de la metafísica clásica. De hecho siguió afirmando, por un lado, la pretendida novedad de la orientación ergonómico-sentiente e intelectual-veritativa de sus respectivas propuestas estrictamente fenomenológicas. Pero a la vez las trató de justificar como una posible prolongación heurística de la anterior vía sapiencial-clásica propia de los hábitos intelectuales de la filosofía griega, a pesar de la clara ruptura que, al menos según sus críticos, se establece entre ellas. En cualquier caso ello no impidió, según Pintor Ramos, la posterior localización de una nueva vía de fundamentación metafísica, o más bien postmetafísica, mediante la simultánea referencia bipolar que ahora se sigue haciendo a un horizonte intelectual-veritativo cada vez más amplio, sin por ello dejar de mantener la anterior referencia fenomenológica obligada a unas primeras impresiones de tipo ergonómico-sentiente $e^{88}$.

En efecto, sólo cuando se afirman en toda su radicalidad esta recíproca interacción de niveles bipolares, a la vez también se les pudo seguir asignando a cada noción básica de la filosofía primera la correspondiente correlación diferenciada de niveles fenomenológicos. Hasta el punto que ahora se pretende justificar así el diverso peso específico que pueden adquirir las nociones más elementales de la filosofía primera, según se adopte un punto de vista fenomenológico, ontológico, semiótico o simplemente práctico, con una doble consecuencia, a saber: por un lado, se pudo mantener el carácter fenomenológicamente inseparable que ahora se atribuye a la correlación diferenciada que se establece entre niveles fenomenológicos antitéticos; por otro lado, se pudo aportar un argumento fenomenológico muy poderoso respecto de la peculiar interacción existente entre inteligencia, actualidad y realidad, sin poder prescindir en ningún caso de ninguna de ellas ${ }^{89}$;

4) Finalmente, el periodo de consolidación correspondiente a la publicación de la trilogía Inteligencia sentiente, publicada entre 1980 y 1983. En efecto, fue entonces cuando trató de compensar la recepción tan criticista que en 1962 tuvo y sigue teniendo Sobre la esencia, resaltando las profundas diferencias de sus propuestas respecto de los planteamientos clásicos. Para conseguirlo trató de consolidar su anterior vía de acceso a una realidad sustantiva fenomenológica concreta y a su correspondiente verdad real total resultante. Para lograrlo siguió

88 Stroud, B. Engagement and Metaphysical Dissatisfaction. Modalyty and Value. Oxford: Oxford University Press, 2011.

89 Wernecke, J. Handeln und Bedeutung. L. Wittgenstein, Ch. S. Peirce und M. Heidegger zu einer Propädeutik einer hermeneutischen Pragmatik. Berlin: Duncker und Humblot, 2007. 
un proceso aparentemente clásico, pero a la vez estrictamente fenomenológico, a saber: el proceso de simple aprensión de la realidad que ahora se logra a través de la razón, la sensibilidad y la inteligencia, siempre que entre ellas se establezca a su vez una profunda interacción de tipo postmetafísico, sin que ninguna de estas tres facultades pueda concebirse con independencia del resto ${ }^{90}$.

En efecto, en los tres casos la post-metafísica exige abrirse a otras tantas totalidades de sentido cada vez más omniabarcantes, pero potencialmente aporéticas. De hecho en los tres casos se justifica una ulterior apertura a un horizonte intelectual-veritativo aún más ilimitado, siempre y cuando simultáneamente se siga manteniendo la exigencia fenomenológica de aportar una referencia a unas primeras impresiones de tipo ergonómico-sentiente proporcionadas al tipo de totalidad de sentido que se pretende justificar. En cualquier caso la referencia fenomenológica a este horizonte intelectual-veritativo por parte de la inteligencia sentiente se concibió como el culmen de un giro personalista muy especial donde ya no se hacía necesaria seguir manteniendo la referencia a una noción de sustancia, sujeto o hipokeimenon racional último al modo aristotélico. En su lugar se hizo notar más bien como para lograr una descripción estrictamente fenomenológica de cada una de estas totalidades de sentido, especialmente respecto de la noción de persona o personeidad, bastaba con tomarlas como un principio constitutivo capaz de apropiarse y reestructurar este tipo peculiar de tensiones bipolares que ella misma genera ${ }^{91}$.

Evidentemente la noción más perjudicada en este tipo de procesos de «desontologización» acabó siendo la propia noción de personeidad o persona. Pretendiendo localizar su núcleo esencial fenomenológico más radical, se acabó en un mero principio formal regulador de este tipo de procesos de apropiación y ulterior reestructuración, tanto del resto de la totalidades con sentido, como de la propia subjetividad, pero perdiendo todo posible rasgo fenomenológico esencial que pudiera caracterizarla. Además, se trataría de un largo proceso reiterativo que se vendría repitiendo desde su artículo de 1921 acerca del pragmatismo, con anterioridad a las oposiciones a cátedra de metafísica de 1926. En efecto, ya entonces denunció los procesos de ontologización que con tanta frecuencia se producían en las diversas corrientes pragmatistas al reducir la persona a una mera función semiótica de utilización de nombres, sin otorgarle ningún contenido

90 Skorupski, J. The Domain of Reasons. Oxford: Oxford University Press, 2010.

${ }^{91}$ Gasparri, G. Le grand paradoxe de M. Descartes. La teoria cartesiana delle verità eterne nell'Europa del XVII secolo. Firenze: Leo S. Olschki, 2007. 
fenomenológico o esencial específico. Sin embargo en sus últimas propuestas de Inteligencia sentiente acabaría ocurriendo algo parecido, cuando advierte que su última noción de realidad personal gira en el vacío, teniéndose que volver a refugiarse en el análisis de la realidad en general, por ver si de este modo encontraba un punto de apoyo en el cual fundamentarse ${ }^{92}$.

Así parece reconocerlo Pintor Ramos, cuando como resumen de la trayectoria intelectual de Zubiri afirma: "Todo apunta a que no era Sobre la esencia sino un amplio estudio sobre La persona. (...) Sin embargo sus esfuerzos no tuvieron el éxito esperado y en 1959 abandonará el proyecto. ¿Por qué fracasa el estudio sobre La persona? Lo cierto es que lo ignoramos, ni siquiera sabemos si fue un fracaso. (....) (Sin embargo) el fracaso del proyecto sobre la persona se torna fecundo en poco tiempo y genera en un estado de ansiedad creciente Sobre la esencia, con un radical cambio de enfoque que no sólo desplaza el interés central a la realidad sino que en buena medida ya hace innecesario el tratamiento independiente de la persona, al menos con la amplitud inicial que se proyectaba» ${ }^{93}$.

Evidentemente estas últimas valoraciones de Pintor Ramos, obligan a formular un contrapunto crítico. Evidentemente el tratamiento dado por Zubiri al problema de la realidad personal no fue lineal, ni tampoco sencillo. Sin embargo parece precipitado afirmar que su fracaso a este respecto se demostró fecundo por haber permitido focalizar todo su interés fenomenológico en la resolución del problema de la realidad, como si precisamente la realidad personal nada tuviera que aportar a este respecto. De todos modos mucho más acertado habría estado si se hubiera resaltado que la localización de las numerosas paradojas y nudos gordianos generados por la propia filosofía primera hizo posible que Zubiri elaborara una nuevo paradigma relacional capaz de justificar los peculiares rasgos metafísicos o más bien postmetafísicos ahora asignados a la realidad personal en particular y a la inteligencia sentiente en general, siempre que a su vez estas dos nociones cumpla con una doble exigencia fenomenológica, a saber: por un lado, seguir haciendo una referencia heurística obligada a aquellas primeras impresiones de tipo ergonómico-sentiente; y, por otro lado, introducir un segundo giro de tipo intelectual-veritativo a la hora de apropiarse y reestructurar aquellas nociones más básicas de la filosofía primera ${ }^{94}$. Y evidentemente en este contexto es totalmente

92 Bennett, K.; Zimmerman, D. W. Oxford Studies in Metaphysics. Oxford: Oxford University Press, 2011.

93 Pintor Ramos, Nudos en la filosofía de Zubiri, 209-211.

${ }^{4}$ Mulhall, S. Guidebook to Heidegger and «Being and Time». Abingdon: Routledge, 2006. 
legítimo considerar que este tipo de paradigmas relacionales fomentan una circularidad de tipo postmetafísico, son meramente formales y totalmente vacíos del mínimo contenido fenomenológico esencial. Sin embargo siempre cabe cuestionar, ¿es legítima esta valoración tan despectiva que ahora Pintor Ramos formula de la noción de persona relacional en Zubiri? En cualquier caso a partir de aquí el debate acerca de la persona relacional se prolongó por otros derroteros en diversos autores, pero ya es momento oportuno de concluir sacando las conclusiones oportunas de los dos debates ahora analizados ${ }^{95}$.

\section{Conclusión: ¿Culminó Zubiri el giro personalista que el mismo inició?}

Gracia, San Baldomero, Corominas y Pintor Ramos coincidieron en atribuir a Zubiri un doble giro ergonómico-sentiente e intelectual-veritativo, en el modo de concebir las nociones más elementales de la filosofía primera. En este contexto se concibió a la persona o personeidad como una inteligencia sentiente con una capacidad efectiva de ejercer un control responsable sobre las inevitables paradojas generadas por los posteriores procesos de «re-ontologización» arbitraria o de ulterior «refundación» fenomenológica justificada de estas misma nociones de la filosofía primera. De todos modos siempre cabe plantearse: ¿Realmente este doble giro fenomenológico tuvo el mismo alcance que el doble giro pragmático y personalista que simultáneamente tuvo lugar en otras muchas corrientes de pensamiento, especialmente en el pragmatismo? A este respecto conviene hacer notar como en las reconstrucciones propuestas por estos cuatro autores se puede comprobar cómo Zubiri terminó recurriendo a cuatro niveles de inteligencia sentiente, de personeidad o persona, con sus correspondientes niveles u horizontes intelectuales-veritativos de comprensión, sin que en todos los casos el desarrollo alcanzado sea similar ${ }^{96}$ :

a) La personeidad o la persona en un sentido estricto, fuerte o absoluto, con dos rasgos fenomenológicos esenciales, al modo como propuso Diego Gracia. En efecto, en este caso la realidad personal se concibe al modo de una inteligencia sentiente, cuyo principio constitutivo o esencia eidética consiste en remitirse a un tipo de impresiones ergonómicas-sentientes claramente desproporcionadas respecto del horizonte intelectual-veritativo de una realidad coactual total resultante al que de un modo metafísico o más bien postmetafísico ahora se remiten. De este

\footnotetext{
95 Inciarte, F.; Llano, A. Metafísica tras el final de la metafísica. Madrid: Cristiandad, 2007.

96 Gómez Cambres, G. La realidad personal. Introducción a Zubiri, Agora, Malaga, 1983.
} 
modo Gracia puso de manifiesto los dos rasgos fenomenológicos principales de la noción de personeidad o persona, concebidos ahora como la correlación bipolar que ahora se establece entre los respectivos actos intencionales de la conciencia, la correspondiente doble realidad extramental-intramental a la que se remiten y la realidad co-actual total en la que se insertan. Se trata de todos modos de dos rasgos fenomenológicos autorreferenciales que en su caso desbordan claramente la noción de persona relacional, por considerarla una noción postmetafísica vacía, meramente formal y carente de contenido fenomenológico esencial. De ahí que Gracia considere necesario remitir estos dos rasgos fenomenológicos a una previa voluntad de verdad que a su vez determina los subsiguientes procesos de apropiación y reestructuración de la respectiva personeidad o persona, a pesar de tampoco poder evitar el vacio postemetafísico que de un modo sobreentendido se reprocha a la noción de persona relacional ${ }^{97}$;

b) La personalidad o carácter en un sentido extrovertido intramundano claramente heterónomo. Al menos así se manifiesta en la inteligencia sentiente cuando se concibe a sí misma como un «yo» o subjetividad frente a los otros «yos», frente al mundo y el resto de los seres, sin vaciarse de su propia esencia autorreferencial, al modo como ahora postulado por San Baldomero. En efecto, en estos casos la inteligencia sentiente pone a prueba su respectiva capacidad de apropiarse y de reestructurar los rasgos fenomenológicos que atribuye al propio "yo» o subjetividad, así como a los demás entes y a la totalidad del Cosmos natural donde se insertan. Hasta el punto que ahora la propia subjetividad o "yo» se asigna a sí misma una capacidad de apropiarse y de reestructurar el conjunto de las totalidades de sentido que le rodean, ya sean meramente mundanales o ya tengan un fuerte carácter epistémico-racional, como al menos ocurrió en el pensamiento clásico griego con las distintas formas de saber. De todos modos ahora se comprueba la necesidad de un punto de vista superior que oriente las subsiguientes relaciones de intencionalidad, religación y colaboración que las correspondientes totalidades de sentido pueden a su vez mantener respecto de la propia subjetividad autorreferencial, respecto de las otras personas o respecto del resto de las totalidades de sentido igualmente mundanales, sin que por ello este peculiar «yo» o subjetividad quede a merced de un ámbito que claramente le supera. De este modo San Baldomero habría descrito correctamente la noción clásica de subjetividad o «yo» en Zubiri. Sin embargo, a diferencia de Gracia, no habría localizado cual fue

97 Ortiz de Landázuri, C. "El sentido del ser en Heidegger, según Apel y Polo: ¿̨Superación del olvido del ser, transcendentalismo autoenajenado o perplejidad insalvable?", Studia Poliana, 4, 2002, 19-60. 
el núcleo fenomenológico esencial de la nueva noción de personeidad o persona relacional de la filosofía primera ${ }^{98}$.

c) La personalidad o carácter, concebida como un "hecho protomoral» de tipo heterónomo, extrovertido y postmoderno, sin necesidad de remitirse a unos presupuestos previos, ya sean de tipo metafísico, crítico-transcendental o pragmáticotranscendental, al modo ahora indicado por Corominas. En efecto, en su caso la inteligencia sentiente también se asigna a sí misma una capacidad de apropiarse y de reestructurar de un modo epistémico-racional los rasgos fenomenológicos de tipo ético que ella misma contrae de un modo responsable frente a los demás hombres o incluso frente a la totalidad de los seres, incluido el propio Cosmos. La personalidad o carácter se configura así como una totalidad con sentido que a su vez pueden reconstruirse de un modo autobiográfico por uno mismo, de igual modo que también se pueden contraponer a las totalidades de sentido encarnadas por los demás agentes sociales. Hasta el punto que ahora la configuración de la propia personalidad o carácter adquiere una clara dimensión heterónoma de tipo ético, metafísico o simplemente postmetafísico, como quedaría de manifiesto en la opción preferencial a favor de los pobres. De este modo Corominas describe correctamente el sentido de la noción de personalidad o carácter en Zubiri. Sin embargo, a diferencia de Gracia, tampoco habría localizado cual habría sido el núcleo fenomenológico esencial de la nueva noción de personeidad o persona relacional de la filosofía primera ${ }^{99}$.

d) Y, finalmente, la noción de persona respectiva o relacional, que a su vez estaría sobreentendida tras los tres anteriores usos dados a la noción de personeidad o persona, como ahora propone Pintor Ramos. Sin embargo ahora sobreviene sobre ella un creciente vaciamiento postmetafísico que sólo permite analizarla indirectamente a través de la noción de la realidad, como si careciera de todo contenido esencial específico, sin tampoco poderla tematizar en la forma como hubiera sido de esperar. En cualquier caso a lo largo de este artículo se ha hecho notar como se trata de un cuarto sentido posible más radical y definitivo al que específicamente se refiere este artículo cuando se interroga: ¿Culminó Zubiri el giro personalista de su filosofía primera? Es decir: ¿Alcanzó este último y defi-

98 Hohwy, J. Kallestrup, J. (eds.) Being Reduced. New Essays on Reduction, Explanation, and Causation. Oxford: Oxford University, 2008.

99 Ortiz de Landázuri, C. "La autodestrucción de la crítica del sentido en Wittgenstein y Heidegger. (A través de Karl-Otto Apel)», Anuario Filosófico, 2000/3, 833-859. 
nitivo sentido de persona respectiva o relacional que a su vez fundamenta y está sobreentendido detrás de todos los demás? ${ }^{100}$

En efecto, en general Zubiri atribuye a la inteligencia sentiente un carácter respectivo o relacional en la medida que ella misma se asigna una capacidad de apropiación y reestructuración no sólo en la medida que también puede hacerse responsable de los rasgos fenomenológicos de los demás, incluida la realidad coactual total resultante o el propio Cosmos, sino que también puede hacerse responsable de aquellos rasgos fenomenológicos que ella se asigna a sí misma. En este sentido la realidad personal no sólo se asigna a sí misma un conjunto de rasgos fenomenológicos autorreferenciales, sino que además entabla un conjunto de relaciones semióticas, sociales o educativas con las demás personas, sin poderse ya considerar un elemento suelto independiente de los demás ${ }^{101}$. Pero de igual modo, también se puede hacer responsable de la posterior marcha de aquellas totalidades con sentido que ella misma pone en macha, ya se trate de la totalidad del Cosmos, del mundo social en su conjunto o de la peculiar personalidad o carácter que el propio «yo» se asigna a sí mismo ${ }^{102}$.

En cualquier caso la noción de persona respectiva o relacional se acabó convirtiendo para Zubiri en la noción más básica de la filosofía primera, dado que a su vez hace posible la correcta intelección de todas las demás. Se trata, además, de la noción más básica que describe el núcleo mismo de la inteligencia sentiente, en la medida que permite justificar el triple modo de concebir las correlaciones de tipo intencional, de religación o de simple colaboración, que siempre cabe hacer respecto de las nociones más básicas de la filosofía primera, según se remitan a sí mismas, a los demás entes o al fundamento relacional compartido por todas ellas. En este sentido la realidad personal recibió por parte de Zubiri un sinnúmero de denominaciones que todavía no se han analizado, como «animal de realidades», «voluntad de verdad religada a lo real», «ex-sistencia» religada», «autopropiedad» originaria, «inteligencia operativa sentiente», «absoluto relativo», «absoluto religado». Evidentemente todo este tipo de definiciones fenomenológicas de la noción de personeidad respectiva o persona relacional están a su vez sobreentendidas tras aquellos otros

100 Basile, F.; Kiverstein, J.; Phemister, P. (eds.) The Metaphysics of Consciousness. Cambridge: Cambridge University Press, 2010.

${ }^{101}$ Ortiz de Landázuri, C. "El personalismo relacional en Karol Wojtyla. La fundamentación de una categoría fenomenológica fundamental, a través de López Quintás, Donati y Apel», en Burgos, J. M. (ed.) La filosofía personalista de Karol Wojtyla. Madrid: Palabra, 2007, 221-239.

${ }^{102}$ Kim, J. Essays in the Metaphysics of Mind. Oxford: Oxford University Press, 2010. 
tres posibles usos ahora indicados de la noción de personeidad o persona, según se tome en un sentido estricto fenomenológico esencial, al modo de Gracia, en un sentido autorreferencial al modo de una subjetividad o "yo», al modo de San Baldomero, en el sentido extrovertido de un mero "hecho protomoral», al modo de Corominas, o en un sentido postmetafísico relacional que debería estar vacío de cualquier tipo de contenido esencial, al modo de Pintor Ramos. De todos modos otorgar un contenido esencial de tipo constitutivo u operativo a esta última noción aún más sofisticada de persona respectiva o relacional es un problema muy complejo, y se tendrá que abordar en otra ocasión ${ }^{103}$.

\section{Bibliografía}

Corominas, Jordi (2000). Ética primera. Aportación de X. Zubiri al debate ético contemporáneo. Bilbao: Desclée de Brouwer.

Gracia, Diego (1986). Voluntad de verdad. Para leer a Zubiri. Barcelona: Labor.

Pintor-Ramos, Antonio (2006). Nudos en la filosofía de Zubiri. Salamanca: Universidad Pontificia de Salamanca.

San Baldomero Ucar, José Manuel (1998). La filosofía de Xavier Zubiri versus la filosofia griega. Madrid: Fundación Universitaria Española.

Recibido: 1/02/2012

Aceptado: 5/07/2012

103 La realidad personal en Zubiri: ¿Principio constitutivo u operativo? Reconstrucción de un debate, Congreso de la SHAF, Teruel, 2010, sin publicar. 